NBER WORKING PAPER SERIES

\title{
DISPERSION IN FINANCING COSTS AND DEVELOPMENT
}

\author{
Tiago V. Cavalcanti \\ Joseph P. Kaboski \\ Bruno S. Martins \\ Cezar Santos \\ Working Paper 28635 \\ http://www.nber.org/papers/w28635 \\ NATIONAL BUREAU OF ECONOMIC RESEARCH \\ 1050 Massachusetts Avenue \\ Cambridge, MA 02138 \\ April 2021
}

Financial support from the Coordenação de Aperfeicoamento de Pessoal de Nível SuperiorBrasil (CAPES)_Finance Code 001 and Faperj and CEPR's STEG research programme is gratefully acknowledged. Kaboski has significant financial relationships with Yale University's YRISE, the IMF, and STEG. The views expressed in this article are those of the authors and do not necessarily represent those of the Central Bank of Brazil, Banco de Portugal, the Eurosystem, or the National Bureau of Economic Research.

NBER working papers are circulated for discussion and comment purposes. They have not been peer-reviewed or been subject to the review by the NBER Board of Directors that accompanies official NBER publications.

(C) 2021 by Tiago V. Cavalcanti, Joseph P. Kaboski, Bruno S. Martins, and Cezar Santos. All rights reserved. Short sections of text, not to exceed two paragraphs, may be quoted without explicit permission provided that full credit, including $(\subset$ notice, is given to the source. 
Dispersion in Financing Costs and Development

Tiago V. Cavalcanti, Joseph P. Kaboski, Bruno S. Martins, and Cezar Santos

NBER Working Paper No. 28635

April 2021

JEL No. E44,O11,O16

\section{ABSTRACT}

Most aggregate theories of financial frictions model credit available at a single cost of financing but rationed. However, using a comprehensive firm-level credit registry, we document both high levels and high dispersion in credit spreads to Brazilian firms. We develop a quantitative dynamic general equilibrium model in which dispersion in spreads arises from intermediation costs and market power. Calibrating to the Brazilian data, we show that, for equivalent levels of external financing, dispersion has more profound impacts on aggregate development than single-price credit rationing and yields firm dynamics that are more consistent with observed patterns.

Tiago V. Cavalcanti

Faculty of Economics

University of Cambridge

Sidgwick Avenue

Cambridge

CB3 9DD

United Kingdom

tvdvc2@cam.ac.uk

Joseph P. Kaboski

Department of Economics

University of Notre Dame

3039 Nanovic Hall

Notre Dame, IN 46556

and NBER

jkaboski@nd.edu
Bruno S. Martins

Central Bank of Brazil

Research Department

Av. Presidente Vargas, 730 - Centro - 14 andar

20071-900 Rio de Janeiro

Brazil

brunosilvamartins@gmail.com

Cezar Santos

EPGE

Fundacao Getulio Vargas

Praia de Botafogo, 190 Sala 1100

Rio de Janeiro - RJ - Brazil

cezarsantos.econ@gmail.com

A data appendix is available at http://www.nber.org/data-appendix/w28635 


\section{Introduction}

The credit market features a sizable gap between lending and deposit rates, and these spreads are larger in poorer countries. According to the International Financial Statistics, the average interest rate spread is approximately 0.7 percent in Japan, 3 percent in the United States, 10 percent in Uruguay and 40 percent in Brazil. Beyond the average spread, micro empirical studies report a high variability in the interest rate charged by lenders for similar loan transactions within the same economy. $\left.\right|^{1}$ Such empirical work examines small subsets of the credit market, however, so that the relevance of spreads and spread variability for the macroeconomy is less clear. Moreover, the quantitative literature assessing the role of financial frictions on development has focused mainly on credit rationing at a fixed zero-spread interest rate. This paper addresses the role of the level and dispersion in financing spreads on economic development and firm dynamics, showing their importance both empirically and quantitatively.

Empirically, we focus on Brazil because of the availability of high quality data that are especially useful for our purposes. We use the Brazilian credit registry, a confidential loan level data set covering all the credit operations in Brazil since January 2005 and containing information on loan characteristics and interest rates. We merge these data with Brazil's linked employer-employee administrative dataset to examine how interest rates and loan size vary with firm characteristics. Even controlling for loan type, loan maturity, a credit risk index, past and future firm default episodes and industry and location fixed effects, the loan interest rate and the volume of credit vary considerably with other firm characteristics, such as firm size and age. In particular, young and small firms pay higher interest rates. For instance, ceteris paribus, a firm with $300 \mathrm{em}-$ ployees pays in interest rates approximately 3 percentage points less than a firm with 30 employees and 5.5 percentage points less than a firm with 3 employees.

Quantitatively, we introduce financing spreads into a standard model of credit-

\footnotetext{
${ }^{1}$ See Banerjee (2003), Banerjee and Duflo (2010), for example. Gilchrist, Sim, and Zakrajsek (2013) provide similar evidence for the U.S.
} 
constrained entrepreneurs and demonstrate their important impact on entrepreneurship, firm dynamics, and economic development, even relative to hard quantity constraints. We start with a continuous-time general equilibrium model with heterogeneous agents and occupational choice. Agents are heterogeneous in their stochastic managerial ability and, at any instant, choose whether to be a worker or an entrepreneur. Following the existing literature, entrepreneurs can acquire capital from intermediaries but face a quantity limit, which can distort a firm's decision away from its optimal level of capital.

We innovate by introducing price-driven distortions in the form of interest rate spreads on externally financed capital. Like quantity constraints, spreads in interest rates distort capital, but they also distort retained income conditional on capital. These interest rate spreads stem from two sources: intermediation costs that decline with productivity and assets and intermediary market power. The productivity-dependent intermediation costs generates fixed variation across firms, while the the asset-dependent costs yield life cycle variation as firms grow. Intermediary market power arises from Nash bargaining between intermediaries and firms. This bargaining creates a dependence of interest rates on ability and wealth through the firms' outside option and the surplus of the transaction. With market power, ceteris paribus, high-productivity firms generate larger surplus and therefore pay higher interest rates. Also, distinct from intermediation costs, intermediary market power distorts financing costs without necessarily distorting the quantity. Taken together, financial frictions help jointly determine the loan size and the interest rate.

We calibrate the model to match key characteristics of the Brazilian economy, including standard macro aggregates as well as firm characteristics and credit market moments based on our micro-level datasets. Both unweighted and credit-weighted average spreads are important moments because they discipline not only the costs of credit that firms face but the extent to which firms borrow at high financing costs. Specifically, the fact that large loans are low interest implies little presence of market power driving spreads, since market power leads to higher interest rates for larger loans; they do not distort loan 
sizes but simply transfer rents to the lender. Instead, calibration attributes most variation in spreads to variation in intermediation costs.

In quantifying the aggregate impacts, the calibrated financial frictions lower output per capita by $31 \%$ relative to a frictionless credit benchmark. Wages fall by $35 \%$, with financial frictions leading to much larger firms. Both lower TFP and lower capital usage play key roles in driving these aggregate results. TFP is $25 \%$ lower and capital is $26 \%$ lower relative to the frictionless credit benchmark.

Counterfactual simulations reveal that spread variation coming from direct intermediation costs drive the vast majority of impacts. First, quantity constraints account for a small fraction of the total losses. Turning off quantity constraints increases GDP by about 7 percentage points, or $20 \%$ of the total losses. Second, turning off spreads accounts for 21 percentage points, or 2/3 of the total losses, split roughly equally between the level and dispersion of spreads. Third, intermediation costs-especially those that fall on low-asset firms-are the most important spread frictions. Market power can also be distortionary, but given the low calibrated level of market power, its contribution is negligible. Finally, the sources of frictions interact with one another, so eliminating one friction has smaller impacts in the presence of others.

To further assess the impacts of spreads, we compare our calibration to an alternative model with only a quantity constraint, similar to the existing literature (e.g., Buera, Kaboski, and Shin, 2011). When both models are calibrated to match the ratio of external finance to GDP, the model with spreads yields larger losses (from the perfect credit benchmark) on all dimensions: 60\% higher losses in output, more than double the losses in TFP, and slightly higher losses in capital. Thus incorporating spreads into models appears quantitatively important, not only for decomposing the source of frictions but for aggregates as well.

We then study how financial frictions affect the dynamics in spreads and firm growth. Both spread and firm growth patterns in the Monte Carlo simulations follow those observed in the data. Moreover, the hump-shaped firm growth patterns in the data are broadly consistent with those in the literature (e.g., Hsieh and Klenow, 2014). The hump-shaped life cycle dynamics in our model 
with spreads is quantitatively closer to the data compared with those of the more typical model with only quantity constraints.

Related Literature. This paper is related to a large literature on the quantitative effects of financial frictions on entrepreneurship and economic development (e.g., Jeong and Townsend, 2007; Antunes, Cavalcanti, and Villamil, 2008; Banerjee and Moll, 2010; Buera, Kaboski, and Shin, 2011; Buera and Shin, 2013; Erosa, 2001; Greenwood, Sanchez, and Wang, 2010; Midrigan and Xu, 2014; Moll, 2014; Moll, Townsend, and Zhorin, 2017; Itskhoki and Moll, 2019). We differ from these papers in two ways. First, most papers in this literature have a single interest rate. When there is a spread, it does not vary within the same economy. Second, these papers typically consider a collateral constraint as the only financial friction. ${ }^{2}$ An exception on both fronts is Greenwood, Sanchez, and Wang (2010), which shows how monitoring technology can generate dispersion in interest rates. However, they abstract from self-financing, a key feature in our model. 3

Micro studies have noted variation in interest rates and their potential for misallocation (e.g., Banerjee and Duflo, 2005, 2010). Some macro papers have looked to measure the extent and quantify the aggregate impact of misallocation among an existing set of firms (e.g., Hsieh and Klenow, 2009; Sraer and Thesmar, 2018; David and Venkateswaran, 2019). Most closely related is the work of Bai, Lu, and Tian (2018) and Gilchrist, Sim, and Zakrajsek (2013). Bai, $\mathrm{Lu}$, and Tian (2018) impute interest rates as the ratio of interest payments to debt for large Chinese firms and relate interest rates to leverage to infer fixed costs. Gilchrist, Sim, and Zakrajsek (2013) directly observe interest rates using contracts of publicly traded bonds in U.S. manufacturing. We complement this work with evidence on spreads for the universe of loans to formal firms, not just large or publicly traded firms where frictions are almost surely less severe, and

\footnotetext{
${ }^{2}$ An exception to the single friction is Moll, Townsend, and Zhorin (2017) which considers an economy with both collateral constraints and moral hazard frictions, but there is regional variation where each agent only faces one of the two frictions and the economy has a single prevailing cost of capital.

3 Besley, Burchardi, and Ghatak (2017) study a model with spread variation but the model is static and variation is purely driven by risk.
} 
we do so for a developing economy. ${ }_{4}^{4}$ We show that the details of contracts matter for understanding spreads. Moreover, because we model entry, we account for losses along the extensive margin, which have been shown to be important (e.g., Buera, Kaboski, and Shin, 2011).

Finally, we follow other researchers in examining firm dynamics in response to credit constraints (e.g., Midrigan and Xu, 2014; Gopinath, Kalemli-Özcan, Karabarbounis, and Villegas-Sanchez, 2017). We are the first to link financial details to firm dynamics, however, and we use both spreads and firm growth to evaluate our key mechanism.

\section{Empirical Analysis}

This section provides a description of our data and documents empirical evidence of the high level and dispersion in financing costs. These patterns provide motivation, inform our modeling strategies, and ultimately discipline our quantitative approach.

\subsection{Data}

Data on bank loans to all formal firms in Brazil are from the Brazilian Public Credit Registry (SCR - Sistema de Informações de Crédito). $!^{5}$ This is a confidential loan-level database, managed by the Central Bank of Brazil. It contains information of all formal loans granted from January 2005 until December 2016. For any bank-to-firm loan during the period of analysis, we identify the lender, borrower, size of the loan, the interest rate on the loan, the loan maturity, default rates, the currency denomination of the loan and whether or not it was at an

\footnotetext{
${ }^{4}$ The Brazilian credit registry data has recently been used by Bustos, Garber, and Ponticelli (2020) to link financial flows and structural transformation.

${ }^{5}$ For more detailed information on the data sets, see Appendix A
} 
earmarked interest rate 6 This dataset allows us to construct information on the borrower-lender relationship, such as the length of a firm-bank relationship. We aggregate loan-level data to the level of the firm using loan-weighted averages to construct annual data on spreads, maturity, non-performing loans, and other measures. Spreads are the difference between the weighted average of firms' outstanding loans rates and the one-year interbank deposit rate..$^{7}$

The second dataset that we use in our empirical analysis is RAIS (Relação Anual de Informações Sociais), a matched employer-employee administrative dataset covering all formal firms in Brazil. This is a mandatory annual survey maintained by the Ministry of Economy. RAIS provides information on firms, such as industry and location, and information on employees, which we use to construct firm-level measures of employment and labor compensation. It is also possible to identify the date of entry and exit of firms. With this dataset, we can capture important firm dynamics for all formal firms in Brazil. Using the unique firm tax identifier, we merge the SCR and RAIS datasets.

\subsection{Empirics}

Here we document the high level and dispersion of spreads. We show that loan characteristics or observed risk explain roughly half of the variation, and other firm characteristics, including firm size and age, explain roughly half of the remaining unexplained variation.

We start with some basic summary statistics on the interest rate spreads, which are high and variable (see Table A1 in Appendix A). Relative to the one-year interbank deposit rate, the average spread in the sample is 44 percentage points and the median spread is about 23 percentage points. There is also large variability in spreads since the standard deviation of the spread rate is 60 percentage points. Some firms pay an interest rate above 100 percentage points in

\footnotetext{
${ }^{6}$ The Brazilian Development Bank (BNDES) is the main financing institution for productive investment in the country, and it offers subsidized interest rates for long-term investments.

${ }^{7}$ Loan maturity is typically short with a mean of 1.2 years and a median of 0.66 . Hence, we found similar patterns using only new loans.
} 
excess of the deposit rate, while other firms with access to earmarked credit, provided often but not exclusively by the BNDES, pay a negative spread.

The variation in spreads follows discernible patterns. Table 1 reports the Ordinary Least Squares (OLS) regression in which the dependent variable is the logarithm of one plus the spread rate. The regressors include loan and borrower characteristics, such as maturity, earmarked credit, length of firm-bank relationship (in months), firm-level controls (e.g., industry, location), and time. There are also controls for proxies for the risk of default of the loan, such as the contemporaneous rate of non-performing loans and the lead and lag of this variable $]^{8}$ There is a positive relationship between the interest rate spread and the rate of non-performing loans of a firm, and a negative correlation between the interest rate spread and the maturity of the loan. The longer the firm-bank relationship, the lower is the spread. This relationship may also capture some (inverse) measure of loan risk. Finally, the higher is the number of banks from which the firm is borrowing, the lower is the spread on its outstanding loans. This may proxy for the extent of competition.

Approximately 12 percent of the observed variation in the spread is explained by the loan characteristics presented in Column 1 of Table 1 , including the rate of non-performing loans at the firm level and the lag and lead of this variable. The introduction of loan type controls increases the explanation of the observed variability in the spreads from 12 to 45 percent, which emphasizes the importance of having loan level data on spreads 9 In our most complete and preferred specification with a full set of different fixed effects (Column (4) of Table 1), approximately 50 percent of the observed variability in the spread at the firm level can be explained by the regressors. Thus, roughly half of the (considerable) variation remains unexplained.

How much of the remaining variability may be predictable for the firm and

\footnotetext{
${ }^{8}$ Including higher order leads and lags does not appreciably impact our conclusions, which may relate to maturity being typically short-term.

${ }^{9}$ These controls are the proportion of credit which is in different type of loans, such as: working capital, investment loans, discounted bill, earmarked credit, and credit to finance international trade.
} 
Table 1: Spreads $\dagger$ and Loan Characteristics..

\begin{tabular}{|c|c|c|c|c|}
\hline & (1) & (2) & (3) & $(4)$ \\
\hline Constant & $\begin{array}{c}0.4285^{* * *} \\
{[41.77]}\end{array}$ & $\begin{array}{c}0.2583^{* * *} \\
{[23.15]}\end{array}$ & $\begin{array}{c}0.2153^{* * *} \\
{[27.45]}\end{array}$ & $\begin{array}{c}0.1255^{* * *} \\
{[13.21]}\end{array}$ \\
\hline Maturity & $\begin{array}{c}-0.0025^{* * *} \\
{[-27.50]}\end{array}$ & $\begin{array}{c}-0.0004^{* * *} \\
{[-17.57]}\end{array}$ & $\begin{array}{c}-0.0004^{* * *} \\
{[-15.70]}\end{array}$ & $\begin{array}{c}-0.0004^{* * *} \\
{[-16.03]}\end{array}$ \\
\hline NPL & $\begin{array}{c}0.2973^{* * *} \\
{[40.52]}\end{array}$ & $\begin{array}{c}0.1604^{* * *} \\
{[20.11]}\end{array}$ & $\begin{array}{c}0.1372^{* * *} \\
{[15.83]}\end{array}$ & $\begin{array}{c}0.1367^{* * *} \\
{[15.55]}\end{array}$ \\
\hline NPL lag (mean) & $\begin{array}{c}0.1259^{* * *} \\
{[13.95]}\end{array}$ & $\begin{array}{c}0.0639^{* * *} \\
{[9.93]}\end{array}$ & $\begin{array}{c}0.0789^{* * *} \\
{[13.82]}\end{array}$ & $\begin{array}{c}0.0758^{* * *} \\
{[13.63]}\end{array}$ \\
\hline NPL lead (mean) & $\begin{array}{c}0.0894^{* * *} \\
{[12.20]}\end{array}$ & $\begin{array}{c}0.0228^{* * * *} \\
{[4.13]}\end{array}$ & $\begin{array}{c}0.0491^{* * *} \\
{[10.57]}\end{array}$ & $\begin{array}{c}0.0488^{* * *} \\
{[10.64]}\end{array}$ \\
\hline Currency dummy & $\begin{array}{c}-0.0096^{* *} \\
{[-2.59]}\end{array}$ & $\begin{array}{c}-0.0061^{*} \\
{[-1.72]}\end{array}$ & $\begin{array}{l}0.0026 \\
{[1.15]}\end{array}$ & $\begin{array}{c}0.0025 \\
{[1.07]}\end{array}$ \\
\hline Firm-bank Relationship & $\begin{array}{c}-0.0001^{* * *} \\
{[-25.86]}\end{array}$ & $\begin{array}{c}-0.0001^{* * *} \\
{[-30.44]}\end{array}$ & $\begin{array}{c}-0.0001^{* * *} \\
{[-29.91]}\end{array}$ & $\begin{array}{c}-0.0001^{* * *} \\
{[-31.99]}\end{array}$ \\
\hline Number of banks & $\begin{array}{c}-0.0433^{* * *} \\
{[-27.25]}\end{array}$ & $\begin{array}{c}-0.0204^{* * * *} \\
{[-18.25]}\end{array}$ & $\begin{array}{c}-0.0162^{* * *} \\
{[-25.23]}\end{array}$ & $\begin{array}{c}-0.0145^{* * *} \\
{[-21.22]}\end{array}$ \\
\hline Observations & $11,846,248$ & $11,846,248$ & $11,846,248$ & $11,846,248$ \\
\hline R-squared & 0.121 & 0.454 & 0.487 & 0.502 \\
\hline Adj R-squared & 0.121 & 0.454 & 0.487 & 0.495 \\
\hline Loan type controls & No & Yes & Yes & Yes \\
\hline Sector FE & No & No & Yes & Yes \\
\hline State FE & No & No & Yes & Yes \\
\hline Firm-type FE & No & No & Yes & Yes \\
\hline Time FE & No & No & Yes & Yes \\
\hline Sector $x$ State $x$ Time FE & No & No & No & Yes \\
\hline Earmarked dummy & No & No & No & Yes \\
\hline RMSE & 0.301 & 0.237 & 0.230 & 0.228 \\
\hline
\end{tabular}

$\dagger$ The dependent variable is the $\log (1+$ spread $)$, where spreads are calculated at the firm level as the credit-weighted average spread on outstanding loans. $t$ statistics in parentheses; ${ }^{*} p<0.1,{ }^{* *} p<0.05,{ }^{* * *} p<0.01$ 
Table 2: Spreads Residuals $\dagger$ and Firm characteristics

\begin{tabular}{lccccc}
\hline \hline & $(1)$ & $(2)$ & $(3)$ & $(4)$ & $(5)$ \\
\hline Constant & $-0.0000^{* * *}$ & $0.0067^{* * *}$ & $0.0416^{* * *}$ & $0.0949^{* * *}$ & $0.0307^{* * *}$ \\
& {$[-586,352.92]$} & {$[57.04]$} & {$[12.62]$} & {$[232.22]$} & {$[5.37]$} \\
Age & & $-0.0007^{* * *}$ & $-0.0041^{* * *}$ & $-0.0000^{* * *}$ & $-0.0042^{* * *}$ \\
& & {$[-66.92]$} & {$[-12.31]$} & {$[-2.94]$} & {$[-13.24]$} \\
Age ${ }^{2}$ & & $0.0000^{* * *}$ & $0.0000^{* * *}$ & $0.0000^{* * *}$ & $0.0000^{* * *}$ \\
& & {$[57.59]$} & {$[11.63]$} & {$[4.30]$} & {$[12.50]$} \\
Wagebill (ln) & & & & $-0.0113^{* * *}$ & $0.0015^{* * *}$ \\
& & & & {$[-229.28]$} & {$[2.75]$} \\
& & & & & \\
\hline Observations & $11,846,248$ & $11,846,236$ & $11,846,236$ & $10,850,982$ & $10,850,982$ \\
Firm FE & Yes & No & Yes & No & Yes \\
R-squared & 0.538 & 0.000 & 0.539 & 0.005 & 0.541 \\
Adj. R-squared & 0.375 & 0.000417 & 0.377 & 0.00543 & 0.376 \\
RMSE & 0.179 & 0.226 & 0.179 & 0.225 & 0.178 \\
\hline \hline
\end{tabular}

$\dagger$ Spread residuals are those from Model (4) in Table 1

$t$ statistics in parentheses; ${ }^{*} p<0.1,{ }^{* *} p<0.05,{ }^{* * *} p<0.01$

perhaps even dependent on characteristics partly endogenous to firm decisions like firm size? To understand this, we regress the residuals of the regression of Column (4) of Table 1 on various firm characteristics ${ }^{10}$ Column (1) of Table 2 regresses residual spread on firm fixed effects. Firm fixed effects absorb idiosyncratic firm characteristics that do not vary over time. It can also capture other persistent features that change little within a ten-year period, such as intangible characteristics like managerial practices (e.g., being a family-run business). Firm fixed effects explain approximately 54 percent of the variability of the residual of the logarithm of one plus the spread rate. Again, these persistent spreads are likely known and predictable from the firm's perspective.

In Columns (2) to (5) of Table 2 we also control for age and size. (All relationships reported in Table 2 are statistically different from zero at $99 \%$ confidence

\footnotetext{
${ }^{10}$ We also run regressions similar to those of Table 1 with added firm-level controls and reach similar conclusions.
} 
level and these correlations hold after we control for a set of loan characteristics and time fixed effects.) Older firms pay lower interest on loans. The agesquared term indicates that this relationship is convex, flattening out with time. Age may proxy for assets, since assets and firm size can be increasing but concave. Lacking capital or output, we use the log of the wage bill as a more direct proxy for firm size ${ }^{11}$ Column (4) indicates that much of the relationship with age is captured by firm size. Firms with large wage bills pay lower spreads, and the significance and magnitude of the age relationship declines after controlling for firm size. However, adding in firm fixed effects in Column (5), the sign of the wage bill coefficient flips, and the role of age is strengthened. If indeed wage bill is proxying for size, much of the fixed effects may also reflect the role of size, whether assets or productivity. Unfortunately, the data and reduced form regression analysis alone do not allow us to distinguish between assets, productivity, or other firm characteristics.

In sum, spreads are high and there is a large dispersion in the spread rate, even after controlling for risks, loan types, and other variables that may drive the cost of lending. Much of the remaining variation is persistent and firm-specific. Spreads fall with firm age, firm size, and the presence of competition in lending. These facts motivate our model, which allows for firm-specific spreads that vary idiosyncratically, exogenously with productivity and assets and endogenously declining with age, and are also impacted by the extent of competition. We return to these data to evaluate additional model implications in Section 5.

\section{Model}

This section develops a model of entrepreneurship decisions and firm dynamics under financial constraints that yields multiple sources of misallocation and dispersion in spreads. We discuss, in turn, the environment, static optimization, dynamic optimization, and equilibrium.

\footnotetext{
${ }^{11}$ We explored different specifications, including using number of employees to proxy for firm size. We also add the variable $\ln ($ loan/wagebill $)$. The results are similar.
} 


\subsection{Environment}

The economy is populated by a continuum of infinitely-lived heterogeneous individuals, who can choose at any time to be either a worker or an entrepreneur. Time is continuous. There is a single good that can be used for consumption or investment and is sold competitively. Entrepreneurs accumulate assets but can augment their own assets with capital from intermediaries. However, financial intermediation suffers from three potential sources of frictions: limited enforcement, intermediation costs, and lender market power.

\subsubsection{Endowments}

At any point in time, $t$, heterogeneous individuals vary by their entrepreneurial productivity, $z(t)$, and their assets, $a(t)$, and they make an occupational choice to be either a worker or an entrepreneur. Entrepreneurial productivity is drawn from an invariant Pareto distribution function $\mu(z)=\eta z^{-(\eta+1)}$ with $z \geq 1$. With Poisson arrival rate $\gamma$, individuals draw a new talent for managing from distribution $\mu(z)$. Agents accumulate or decumulate assets subject to their consumption decisions and budget constraint.

\subsubsection{Preferences}

Individuals derive utility from consumption, $c(t)$, and preferences are represented by:

$$
E_{0}\left[\int_{0}^{\infty} e^{-\rho t} u(c(t)) d t\right],
$$

where $\rho$ is the subjective discount rate, and $E_{0}$ is the expectations operator conditional on information at $t=0$. The period utility takes the following form:

$$
u(c(t))=\frac{c(t)^{1-\sigma}-1}{1-\sigma}, \sigma>0
$$




\subsubsection{Technology}

Entrepreneurs operate a technology that uses labor, $n(t)$, and capital, $k(t)$, to produce a single consumption good, $y(t)$ :

$$
y(t)=z(t) k(t)^{\alpha} n(t)^{\theta}, \text { with } \theta, \alpha \in(0,1), \text { and } \alpha+\theta<1 .
$$

Entrepreneurs incur a fixed-cost $\kappa \geq 0$ to operate at any time and can operate only one project. They hire labor and may finance capital through their own assets, by borrowing from financial intermediaries, or a combination of the two.

\subsubsection{Financial Intermediation}

A continuum of financial intermediaries with unit mass offers agents an option to deposit assets at an endogenously-determined competitive rate $r(t)$ or borrow additional capital, where both the loan amount $l(t)$ and the borrowing interest rate $\tilde{r}(t)$ are subject to financial frictions. We model three sources of frictions: the typical limited enforcement that constrains loan sizes by the fraction of income stream that the intermediary recovers, and spreads on borrowing rates that come from real intermediation costs and lender market power. For simplicity, we model static, one-time loan relationships, in which an entrepreneur meets a financial intermediary and enters into negotiation to determine the amount and the interest on a loan. For ease of expression, we drop the time indexes in discussing the financial intermediation technology and static optimization. Since we solve for a stationary equilibrium, these relationships will not vary with time. The individual state vector $(a, z)$ will be sufficient.

The real intermediation cost associated with making a loan $l=k-a$ to an entrepreneur who has collateral $a$ and productivity $z$ is $g(l, \tau(a, z))$. This cost is associated with collecting information about borrowers, monitoring, and enforcing credit contracts. Otherwise, borrowers could break their promise with- 
out any penalty. We denote this intermediation cost by

$$
g(l, \tau(a, z))=l \tau(a, z)
$$

where

$$
\tau(a, z)=\tau_{0}+\frac{\tau_{a}}{1+a}+\frac{\tau_{z}}{1+z}, \text { with } \tau_{0} \geq 0, \tau_{a} \geq 0 \text { and } \tau_{z} \geq 0
$$

We model per unit intermediation costs that are (weakly) decreasing in both productivity, $z$, and assets, $a$. The former captures a measure of cash flow and the latter captures a measure of collateral, two commonly-evaluated lending criteria 12

Market power comes from the bilateral nature of borrowing/lending opportunities. The lender and borrower negotiate over the interest rate $\tilde{r}$ and loan amount $l$ via Nash bargaining, where $\chi \in[0,1]$ denotes the intermediaries' bargaining power.

The range of possible loans over which the lender will bargain is constrained by the limited enforcement of contracts, however. Limited enforcement means borrowers have the option to strategically default and lenders can only recover a fraction $\phi$ of the output produced net of labor costs. $\phi$ is therefore a measure of financial enforcement, and will lead to a quantity restriction that is common in the literature (e.g., Buera, Kaboski, and Shin, 2011). For simplicity, we follow this literature in modeling only static penalties for defaulting.

\subsection{Static Optimization}

Given the continuous-time set up, occupational choice, intermediary meeting, negotiation, contracting, disbursal, and repayment all happen contemporaneously. We now solve for static quantities, including occupational choice, con-

\footnotetext{
${ }^{12}$ Bai, Lu, and Tian (2018) model intermediation costs that are decreasing in loan size. Intermediation costs that vary with loan size, while reasonable, would introduce an additional nonlinearity into the static optimization, increasing the required computation substantially.
} 
tract terms, factor usage, and instantaneous income.

\subsubsection{Entrepreneurial Profits}

Static entrepreneurial profits are subject to multiple frictions. Entrepreneurs can freely hire labor at wage $w$, but may face different costs for external capital, $\tilde{r}$, and internal capital, $r$. Given the fixed cost, $\kappa$, the flow of income of an entrepreneur with asset $a$ and productivity $z$ using capital $k$ and labor $n$ is:

$$
\pi(k, n, \tilde{r} ; a, z)=z k^{\alpha} n^{\theta}-w n-\tilde{r}(k-a)-r a-\kappa .
$$

Entrepreneurs maximize (4) given factor prices and their choice set for capital. Solving the constrained static optimization involves first solving for the entrepreneur's unconstrained capital level (denoted by $k^{u}(z)$ ) and comparing it with the entrepreneur's assets (see the Appendix for details). Then, for those with assets below their unconstrained capital, we solve for the set of capital levels satisfying the limited enforcement constraint:

$$
\pi(k, \tilde{r} ; a, z) \geq(1-\phi)(x(k, \tilde{r} ; a, z)+\tilde{r}(k-a))-r a-\kappa,
$$

where $\pi(k, \tilde{r} ; a, z)$ denotes entrepreneurial profits and $x(k, \tilde{r} ; a, z) \equiv$ $\max _{n \geq 0}\{\pi(k, n, \tilde{r} ; a, z)\}+\tilde{r}(k-a)+r a+\kappa$ is output net of labor costs, both expressed as a function of capital given the optimal choice of labor. The left-hand side of the constraint is therefore income from repayment, which must exceed the income from defaulting. This income in default is expressed on the right-hand side as the retained fraction, $1-\phi$, of the total unrepaid loans and output (net of labor costs), netting out foregone interest on unborrowed capital and the fixed cost from this retained fraction. When the expression holds with equality, it defines a hard quantity constraint on borrowing, i.e., a maximum level of capital (and implicitly a maximum loan size) that depends on the borrowing rate, $\bar{k}(\tilde{r})$.

For an entrepreneur who borrows, the loan size, $l$, quantity of capital, $k^{b}$, and 
the borrowing rate, $\tilde{r}$, are the solution to the bargaining problem:

$$
\max _{\bar{k} \geq k \geq a, \tilde{r}}[(\tilde{r}-r-\tau(a, z))(k-a)]^{\chi}[\pi(k, \tilde{r} ; a, z)+\tilde{r}(k-a)-\tilde{w}(a, z)]^{1-\chi} .
$$

The first term (raised to the $\chi$ power) is the intermediary's surplus $\left(S^{b}\right)$ from the loan. The second term (raised to the $1-\chi$ power) is the surplus to the entrepreneur $\left(S^{e}\right)$. The expression $\tilde{w}(a, z)$ is the best outside option of the borrowing entrepreneur, either: (i) the entrepreneurial profits from operating the business with internal capital only or (ii) the wage from becoming a worker. (Formally, $\tilde{w}(a, z)$ is defined as $\max \{w, x(a, z)-r a-\kappa\}$ or, equivalently, $\max \{w, \tilde{\pi}(a, z)\}$.) The solution to this problem defines a financing spread $\tilde{r}-r$ that depends on the intermediation costs and the bargaining power of the intermediary.

When the contracted capital, $k^{b}$, satisfies a strict inequality (i.e., $k^{b}<\bar{k}(\tilde{r})$ ), one can use the first-order conditions to solve for the contract terms:

$$
k^{b}(a, z)=\left(z\left(\frac{\alpha}{r+\tau(a, z)}\right)^{(1-\theta)}\left(\frac{\theta}{w}\right)^{\theta}\right)^{\frac{1}{1-\alpha-\theta}}
$$

and

$$
\tilde{r}(a, z)=r+\tau(a, z)+\chi\left(\frac{\left.\pi^{b}(a, z)-\tilde{w}(a, z)\right)}{k^{b}(a, z)-a}\right) .
$$

Equation (5) corresponds to the optimal level of contracted capital for given intermediation costs, $\tau(a, z)$. Indeed, if $\tau(a, z)=0$, this would be the unconstrained level of capital. However, in equation (6), when the intermediary has market power, i.e., $\chi>0$, the loan interest $\tilde{r}(a, z)$, will be distorted even in the case of $\tau(a, z)=0$. Thus, intermediary market power will not statically distort capital but will impact the profits of the entrepreneur, and will therefore dynamically impact the entrepreneur's ability to self-finance. Moreover, the borrowing interest rate will vary with assets $a$ and productivity $z$, as these determine the loan size and the entrepreneur's flow surplus. We characterize elements of this dependence in the proposition below. 
Proposition 1 Consider an agent $(a, z)$ such that $a<k^{u}(z), k<\bar{k}(\tilde{r})$ and $S^{e}(a, z) \geq$ 0 .

1. Case of $\chi=0$ :

$$
\begin{gathered}
\tilde{r}(a, z)=r+\tau(a, z), \\
\frac{\partial \tilde{r}(a, z)}{\partial z} \leq 0 \text { and } \frac{\partial k^{b}(a, z)}{\partial z} \geq 0 ; \frac{\partial \tilde{r}(a, z)}{\partial a} \leq 0 \text { and } \frac{\partial k^{b}(a, z)}{\partial a} \geq 0 .
\end{gathered}
$$

2. Case of $\chi \in(0,1)$ and $\tau(a, z)=\tau_{0} \geq 0$ : $\frac{\partial \tilde{r}(a, z)}{\partial \chi}>0$ and $\frac{\partial k^{b}(a, z)}{\partial \chi}=0$.

3. Case of $\chi=1$ and $\tau(a, z)=\tau_{0} \geq 0$ :

$$
\begin{gathered}
\tilde{r}(a, z)=r+\tau_{0}+\frac{1}{k^{b}(a, z)-a}\left(y^{b}(a, z)+\tau_{0} a-\kappa-\tilde{w}(a, z)\right), \\
\frac{\partial \tilde{r}(a, z)}{\partial z}>0 \text { and } \frac{\partial k^{b}(a, z)}{\partial z}>0 \text {. In addition, if } w>\tilde{\pi}(a, z), \text { then } \frac{\partial \tilde{r}(a, z)}{\partial a}>0 \text { and } \\
\frac{\partial k^{b}(a, z)}{\partial a}=0 ; \text { and if } w<\tilde{\pi}(a, z), \text { then } \frac{\partial \tilde{r}(a, z)}{\partial a}<0 \text { and } \frac{\partial k^{b}(a, z)}{\partial a}=0 .
\end{gathered}
$$

Proof. See Appendix B.1

Proposition 1 shows how assets, productivity, and bargaining power affect the loan interest rate and the size of the loan when the limited commitment constraint does not bind. The first case isolates the role of intermediation costs by focusing on the case with no intermediary bargaining power $(\chi=0)$ : the loan interest rate equals the marginal cost of a loan, $\tilde{r}(a, z)=r+\tau(a, z)$. Following the intermediation costs, the loan interest rate varies negatively with the productivity $z$ and assets $a$, and the capital used by entrepreneurs is consequently increasing in assets and productivity. The variation in intermediation costs therefore leads to dispersion in both borrowing rates and the marginal productivity of capital among borrowing entrepreneurs.

The second case illustrates the direct influence of intermediate levels of market power. Market power does not influence the level of capital, since this is chosen to maximize total surplus. Instead, the loan interest rate simply increases with market power, since this is the intermediary's tool for capturing surplus. Hence, market power alone does not cause intensive margin misallocation. Nevertheless, the dynamic effects of the dispersion of loan interest rates 
on the distribution of assets might still influence whether or not the limited enforcement constraint binds and the extent of intermediation costs.

The third case looks at the extreme case of the intermediary having full bargaining power $(\chi=1)$. When this is the case and intermediation costs are independent of assets and productivity $\left(\tau(a, z)=\tau_{0}\right)$, then Proposition 1 shows that the loan interest rate will still vary with the entrepreneur's type $(a, z)$. However, market power leads loan interest rates to be increasing in productivity. For a given $a$, a higher $z$ implies a higher entrepreneurial surplus, which is captured through the higher loan interest rate charged by financial intermediaries. Whether the loan interest rate is increasing or decreasing in assets depends on whether the outside option is the wage or self-financed entrepreneurship. When $\tilde{\pi}(a, z)>w$, a higher level of assets increases the outside option of an entrepreneur, and so the loan interest rate decreases with assets. When $\tilde{\pi}(a, z)<w$, the outside option is independent of $a$. Since the loan size decreases with $a$, however, the loan interest rate increases to capture the same share of surplus. In this case of pure market power, we would observe dispersion in spreads but no dispersion in marginal productivity of capital.

When the enforcement constraint binds, $k=\bar{k}(\tilde{r})$, the following optimality conditions solve for the constrained level of capital $k^{b}$ and loan interest rate $\tilde{r}$ :

$$
\phi x(k, z)=\tilde{r}(k-a)
$$

and

$$
\chi S^{e}\left(\phi \frac{\partial x(k, z)}{\partial k}-r-\tau(a, z)\right)+(1-\chi) S^{b}(1-\phi) \frac{\partial x(k, z)}{\partial k}=0 .
$$

Proposition 2 summarizes the main results for the case in which the enforcement constraint binds.

Proposition 2 Consider an agent $(a, z)$ such that $a<k^{u}(a, z)$, the incentive compatible constraint binds and $S^{e}(a, z) \geq 0$. 
1. Case of $\chi=0$ :

$$
\begin{gathered}
\tilde{r}(a, z)=r+\tau(a, z), \\
\frac{\partial \tilde{r}(a, z)}{\partial z} \leq 0 \text { and } \frac{\partial k^{b}(a, z)}{\partial z}>0 ; \frac{\partial \tilde{r}(a, z)}{\partial a} \leq 0 \text { and } \frac{\partial k^{b}(a, z)}{\partial a}>0 .
\end{gathered}
$$

2. Case of $\chi \in(0,1)$ and $\tau(a, z)=\tau_{0} \geq 0: \frac{\partial \tilde{r}(a, z)}{\partial \chi}>0$ and $\frac{\partial k^{b}(a, z)}{\partial \chi}<0$.

3. Case of $\chi=1$ and $\tau(a, z)=\tau_{0} \geq 0$ :

$$
\begin{gathered}
\tilde{r}(a, z)=\frac{\phi x\left(k^{b}(a, z)\right)}{k^{b}(a, z)-a} . \\
\text { If } w>\tilde{\pi}(a, z) \text {, then } \frac{\partial \tilde{r}(a, z)}{\partial \tilde{r} z}>0 \text { and } \frac{\partial k^{b}(a, z)}{\partial z}<0 ; \text { and } \frac{\partial \tilde{r}(a, z)}{\partial \tilde{r}(a, z)} \gtreqless 0 \text { and } \frac{\partial k^{b}(a, z)}{\partial a}>0 . \\
\text { If } w<\tilde{\pi}(a, z) \text {, then } \frac{\partial(a, z)}{\partial z} \gtreqless 0 \text { and } \frac{\partial k^{b}(a, z)}{\partial z} \gtreqless 0 ; \text { and } \frac{\partial \tilde{r}(a, z)}{\partial a} \gtreqless 0 \text { and } \frac{\partial k^{b}(a, z)}{\partial a}>0 .
\end{gathered}
$$

\section{Proof. See Appendix B.2}

In the first case, when $\chi=0$, the results are similar to those in Proposition 1 . However, in the second case, as the intermediary gets market power, it must trade off a higher interest rate with less capital, since the incentive to default involves the product of the interest rate and loan amount. When $\chi=1$ and the enforcement constraint binds, it is not straightforward to characterize how assets and productivity change the interest rate and the optimal loan size.

After bargaining and optimization, instantaneous entrepreneurial profits are then:

$$
\pi^{*}(a, z)= \begin{cases}x(a, z)-r a-\kappa, & \text { if } l=0 \\ x\left(k^{b}, z\right)-\tilde{r}\left(k^{b}-a\right)-r a-\kappa, & \text { if } l>0,\end{cases}
$$

where the greater of the two is chosen. Financial distortions will impact the income of a borrowing entrepreneur in two ways. First, a below-optimal level of capital, i.e, $k^{b}<k^{u}$, will reduce profits through its impact on $x\left(k^{b}, z\right)$, since the marginal product of capital will exceed $r$. Second, for a given level of capital, a higher cost of borrowing, $\tilde{r}>r$, will reduce profits through its impact on capital costs, $\tilde{r}\left(k^{b}-a\right)$. Profitability will naturally impact decisions about entry and dynamic accumulation, which we turn to now. 


\subsubsection{Occupational Choice}

At every moment, agents have the option to either work at a wage $w$ or as an entrepreneur and earn profits. The decision is static and so they make this decision to maximize their current income flow, $I(a, z)=\max \left\{w, \pi^{*}(a, z)\right\}$. Define the policy function $o(a, z)$ such that $o(a, z)=1$ if the individual becomes an entrepreneur and zero otherwise.

Financial frictions will influence not only the allocation of capital, but the occupational choice as well. We illustrate this in Figure 1, which shows the occupational choice in $(a, z)$ space for agents facing $\chi=0$ (perfect competition in the banking sector), a given wage rate, $w$, and interest rate, $r$, and two levels of the enforcement variable, $\phi$. Appendix B.3 contains the formal derivation of the two graphs presented in Figure 1.

Figure 1(a) shows the case of perfect enforcement, i.e., $\phi=1$, and costly financial intermediation, $\tilde{r}(a, z)-r>0$. The horizontal line $z^{u}$ illustrates the cutoff for entrepreneurship in a world with no financial frictions. In this world, all agents with productivity $z>z^{u}$ would become an entrepreneur producing at their optimal scale regardless of their wealth, and would share the same marginal productivity of inputs. With financial frictions, however, this is not the case. The threshold is now wealth dependent as illustrated by the solid line $z^{e}(a)$. The white region below $z^{e}(a)$ indicates that the extensive margin is distorted as some low-wealth agents become workers despite productivities above the perfect credit $z^{u}$ threshold. The dark gray shaded area (region B) represents the entrepreneurs who are borrowers. They pay different loan interest rates, depending on their asset $a$ and productivity $z$, and so the marginal product of capital varies over this region. Agents in the darker region close to the $z^{e}(a)$ line pay higher interest rates, borrow more, and produce with a higher marginal product of capital. Agents close to the dotted line $\bar{a}^{u}(z)$ pay a lower interest rate, borrow less, and have a marginal productivity of capital closer to the internal cost of capital, $r$. The light gray shaded area (region U) displays the agents who are unconstrained entrepreneurs: their wealth exceeds unconstrained capital, $a \geq k^{u}(z)$. Agents in this region produce at their optimal 
Figure 1: Occupational choice, $\chi=0$.

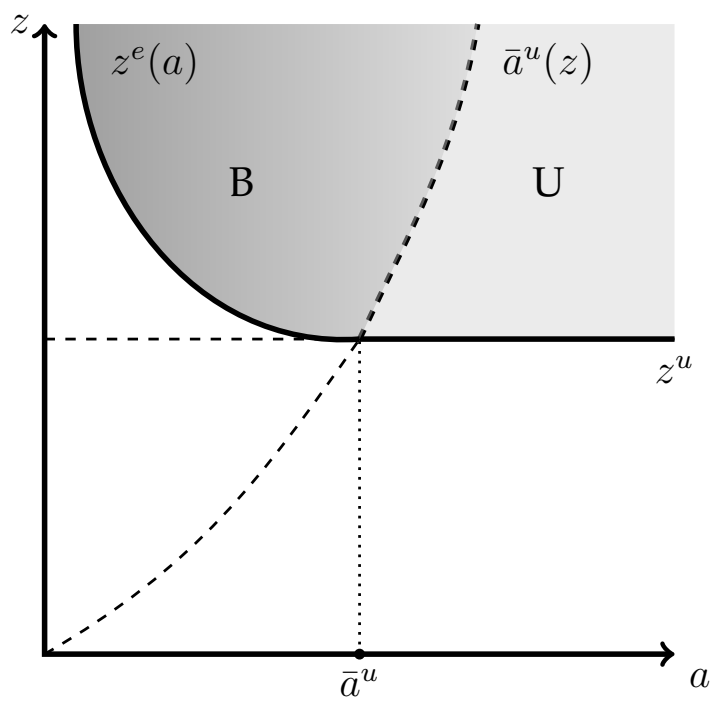

(a) Full enforcement, $\phi=1$.

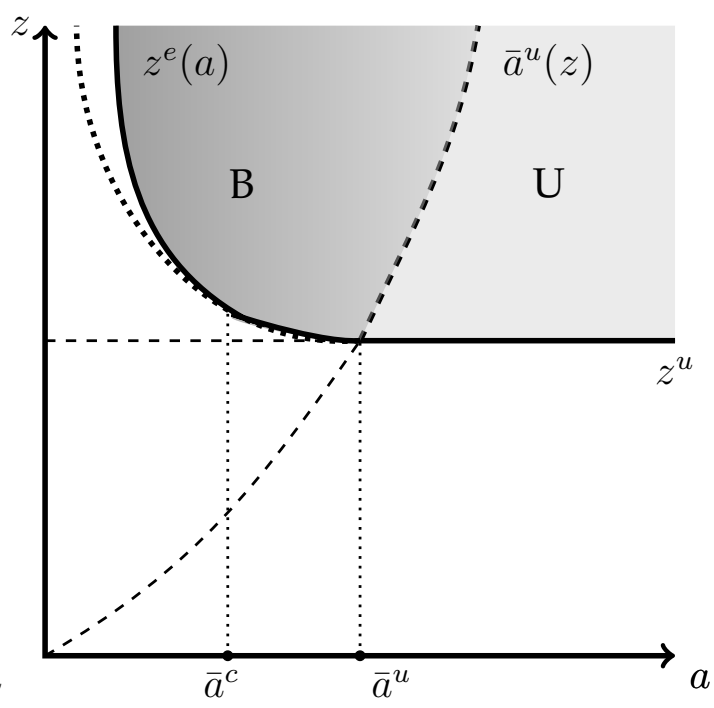

(b) Imperfect enforcement, $\phi<1$.

Notes: The light gray shaded area, $\mathbf{U}$, contains the measure of unconstrained entrepreneurs. The dark gray shaded area, $\mathbf{B}$, displays the measure of constrained borrowers. The white area below the curve $z^{e}(a)$ represents the measure of workers.

scale without borrowing and share the same marginal productivity of inputs. Among these entrepreneurs, there is no misallocation of capital.

Figure 1(b) displays the case in which the enforcement of financial contracts is imperfect, such that $\phi<1$. We still assume that $\chi=0$. There are two differences compared with perfect enforcement. First, the line $z^{e}(a)$ becomes steeper when this constraint starts to bind at $\bar{a}^{u}$. That is, imperfect enforcement of financial contracts affects the extensive margin, further constraining poor yet talented agents from becoming entrepreneurs. Second, imperfect enforcement also impacts the intensive margin of the allocation of capital. Focusing on Region $B$, the entrepreneurs who borrow, as we get closer to the solid line $z^{e}(a)$, the enforcement constraint binds and entrepreneurs will be producing with a marginal productivity of capital that is above the loan rate they face. However, agents in region $B$ close to the dotted line $\bar{a}^{u}(z)$ are not limited by the enforcement constraint. Such agents produce with a marginal productivity of capital similar to the loan rate, which varies with their asset and productivity. Region U still 
represents the unconstrained entrepreneurs.

\subsection{Dynamic Optimization}

We turn now to the dynamic optimization, which simply involves a savings decision and the stochastic death of entrepreneurial productivity, $z$, and replacement with a new one, some $\tilde{z}$.

Given the static optimization that yields instantaneous income, $I(a, z)$, the budget constraint governing the assets of an entrepreneur $(a, z)$ is:

$$
\dot{a}(a, z)=I(a, z)+(r-\delta) a-c(a, z) .
$$

Note that distortions to $k^{b}$ and $\tilde{r}$ simply influence the dynamics of asset accumulation (and likewise firm growth) through their impacts on income, $I(a, z)$.

They will also influence the dynamics of asset accumulation through the choice of $c(a, z)$ because they impact the incentives to accumulate through the value function and continuation value. Let $V(a, z)$ be the stationary value for individual with the current state $(a, z)$. The value function satisfies the following stationary Hamilton-Jacobi-Bellman (HJB) equation:

$$
\begin{gathered}
\rho V(a, z)=\max _{c} u(c)+\partial_{a} V(a, z)(I(a, z)+(r-\delta) a-c)+ \\
\gamma\left[\int_{\mathcal{Z}} V(a, \tilde{z}) \mu(\tilde{z}) d \tilde{z}-V(a, z)\right]
\end{gathered}
$$

\subsection{Equilibrium}

We solve for a stationary competitive equilibrium ${ }^{13}$ Individuals differ from one another with respect to their asset and entrepreneurial abilities, $(a, z)$. Given the invariant distribution of abilities $\mu(z)$, the stationary competitive equilibrium of this economy consists of a stationary distribution of states $(a, z), H(a, z)$, in-

\footnotetext{
${ }^{13}$ Given the continuous-time setup, we can use an efficient numerical algorithm based on Achdou et al. (2021)
} 
duced by the decision of the agents and the distribution $\mu(z)$. Prices are given by the wage rate $w$, the rental price of capital $r$, and loan interest rates $\tilde{r}(a, z)$. Individuals' optimal behavior was described in detail above and the policy functions associated with their optimal decisions are $k(a, z), n(a, z), o(a, z)$ and $c(a, z)$. These decisions are consistent with the recursive problem of all agents and with the financial contracts. It remains, therefore, to characterize the market equilibrium conditions and the aggregate law of motion:

1. Equilibrium in the capital market:

$$
K:=\int_{\{o(a, z)=1\}} k(a, z) H(d a, d z)=\int a H(d a, d z) .
$$

2. Equilibrium in the labor market:

$$
N:=\int_{\{o(a, z)=1\}} n(a, z) H(d a, d z)=\int_{\{o(a, z)=0\}} H(d a, d z) .
$$

3. Final goods:

$$
\begin{array}{r}
\int c(a, z) H(d a, d z)+\int_{\{o(a, z)=1, k(a, z)>a\}} \tau(a, z) H(d a, d z)= \\
\int_{\{o(a, z)=1\}} y(a, z) H(d a, d z)-\delta K .
\end{array}
$$

4. The joint distribution $h(a, z)$ evolves according to the following Kolmogorov Forward equation:

$$
0=-\frac{d}{d a}[\dot{a}(a, z) h(a, z)]-\gamma h(a, z)+\gamma \mu(z) \int h(a, \tilde{z}) d \tilde{z} .
$$

We have assumed that financial intermediaries' profits are spent outside the economy. Finally, a variant of this fully general equilibrium is that of a small open economy which faces a fixed interest rate, $r$. In this case, the interest rate is assigned from outside the model, and the capital market clearing equation is dropped as an equilibrium condition. 


\section{Calibration}

To discipline our quantitative exercises, we calibrate the model to be consistent with macro and micro moments of the Brazilian economy. Our approach is to assign standard values for two parameters common in the literature, and then to jointly calibrate the remaining parameters of the model to the private sector of Brazil during the period 2005-16.

The two assigned values are the inverse intertemporal elasticity of substitution parameter, $\sigma=1.5$, and the depreciation rate, $\delta=0.06$. The intertemporal elasticity is in line with most of the literature on consumption surveyed by Attanasio and Weber (2010) and also with the Brazil-specific literature that estimates $\sigma$ in the range from 1 to 3 (e.g., Gandelman and Hernández-Murillo, 2014; Fajardo, Ornelas, and Farias, 2012). The depreciation rate is commonly used in the macro growth literature.

The remaining 11 parameters are jointly calibrated to match a set of 12 relevant moments characterizing firm dynamics, concentration, and credit markets. ${ }^{14}$ Firm dynamics and concentration are important determinants of the equilibrium distribution of productivity and wealth. The credit market characteristics help discipline the distortions themselves. The parameters are jointly determined, but we give a rationalization for the choice of moments parameter-byparameter below.

Our benchmark is a closed economy. ${ }^{15}$ We calibrate the subjective discount rate, $\rho=0.25$, to match the average real risk-free interest rate over the period from 2005 to 2016 . We calculate the risk free real interest rate as the difference between the real interest rate on Brazilian treasury bills of roughly $6 \%$ and the sovereign default risk premium of about $4 \%$.

The production function exponents on capital, $\alpha=0.29$, and labor, $\theta=0.35$, are

\footnotetext{
${ }^{14}$ The definition, value, and source of the moments are detailed in Appendix A.2.

${ }^{15}$ In Appendix C, we present a calibration and counterfactual experiments in a small open economy in which we target the net international asset position of Brazil. There arises a distinction between assets and capital, and financial frictions are less severe in an open economy with fixed interest rate, but the key messages of the paper are robust to an open economy.
} 
disciplined by the the share of income paid to capital and the earnings share of the right tail, since $1-\alpha-\theta$ is the share of entrepreneurial income, which is captured in the tail. For Brazil, capital's share can be calculated from the Penn World Tables (PWT) 9.1, and over the years of interest it averages to be 0.40 , the same value reported by Abeles, Amarante, and Vega (2015) ${ }^{16}$ For the income tail, we target the fact that top $10 \%$ of earners receive $56 \%$ of total income, according to Morgan (2017). Finally, the fixed cost, $\kappa=1.02$, helps define the minimum efficient scale for an entrepreneur, and hence the average firm size, which we calculate in our data to be 21 employees per firm.

Next, we have two parameters that determine the distribution and dynamics of productivity. The Pareto parameter, $\eta=3.47$, determines the thickness of the productivity tail, and is disciplined by the relative importance of large firms in the tail. We target the share of the top $10 \%$ of firms in total employment of 0.78 , which we calculate in our data. The Poisson arrival rate of a new productivity draw, $\gamma=0.15$, is disciplined by the exit rate of establishments, which we calculate to be 0.08 in the data.

Finally, we have five parameters related to the financial sector: the limited enforcement quantity parameter, $\phi=0.12$, the intermediation technology parameters, $\tau_{0}=0.01, \tau_{a}=0.68$ and $\tau_{z}=0.23$, and the intermediaries' bargaining power in financial contracting, $\chi=0.03$. We discipline these parameters to match the overall level of financial development, measured as the ratio of external finance to GDP, which averages 0.49 , and moments targeting the distribution of credit and spreads. In our data, $35 \%$ of entrepreneurs have credit. The average spread is high, 38 percentage points, and varied, with a standard deviation of 32 percentage points ${ }^{17}$

\footnotetext{
${ }^{16}$ The detailed capital services file reports the shares paid to labor and land/natural resources, and the remaining share is capital's share. PWT uses Gollin (2002)'s Method 2 for Brazil, attributing proprietary income to labor and capital according to the split of nonproprietary income. We follow the same method for measurement in the model, attributing a fraction $\alpha /(\alpha+\theta)$ of entrepreneurial income to capital. Entrepreneurial income is important, however, so the subtleties of its treatment have large impact on capital's share in both data and model.

${ }^{17}$ This is different from the simple average spread and simple standard deviation of spreads presented in Table A1. We washed out factors from the data which are not present in our model, such as differences in maturity and non-performing loans. We accomplish this by using
} 
However, the credit-weighted average spread is a much lower value of $6 \%$. The difference between the two indicates how correlated the use of credit is with spreads; large firms pay lower spreads and are also the larger borrowers. Comparing the credit-weighted spread of 0.06 with the value of $\tau_{0}$ of $0.01,1 / 6$ of the weighted spread comes from intermediation costs which do not vary with firm characteristics. To put the spread-inducing parameters $\left(\tau_{a}, \tau_{z}\right.$, and $\left.\chi\right)$ into perspective, consider two extremes. The intermediation costs imply that an entrepreneur with no assets and a minuscule productivity would face a spread of 92 percentage points, coming purely from intermediation costs. Similarly, a very productive entrepreneur with no assets-with profits about three times the equilibrium wage-would pay a spread of about 45 percentage points, a mix of intermediation costs and market power.

The above discussion about parameter values and calibration targets are summarized in the top panel of Table 3, while the model fit is shown in the bottom panel. The calibrated values of common parameters generally compare well with previous calibrations in the literature. The micro returns to scale $(\alpha+\theta)$, Pareto parameter $(\eta)$, and quantity constraint $(\phi)$ all fall in the range (and indeed between) those in similar models calibrated for the United States (e.g., Buera, Kaboski, and Shin, 2011) and India (e.g., Buera, Kaboski, and Shin, 2020). The value of $\kappa$ is between those calibrated for services and manufacturing in the two-sector calibration in Buera, Kaboski, and Shin (2011). The model is therefore a close calibration to the existing literature, except that we require a high discount rate to assure that firms borrow despite the high spreads.

With more moments than parameters, the overall fit of the model is good though not perfect. The high level of spreads, high dispersion in spreads, and high fraction of borrowers are only achievable for a restricted set of parameters. These require the capital's share of income to be somewhat smaller than in the data, though within the range of commonly accepted values. Moreover, the investment rate in the model is somewhat lower than in the data, a result of the larger subjective discount rate required to match the credit moments.

regression (4) in Table11. See Appendix A.2 for more details. 
Table 3: Calibration and Model Fit

\begin{tabular}{|c|c|c|c|}
\hline \multicolumn{3}{|c|}{ Parameter Values } & \\
\hline Parameter & Description & & Value \\
\hline \multicolumn{4}{|c|}{2 assigned parameters } \\
\hline$\sigma$ & \multicolumn{2}{|c|}{ Coefficient of relative risk aversion } & 1.50 \\
\hline$\delta$ & \multicolumn{2}{|c|}{ Depreciation rate } & 0.06 \\
\hline \multicolumn{4}{|c|}{11 calibrated parameters } \\
\hline$\rho$ & \multicolumn{2}{|c|}{ Subjective discount rate } & 0.25 \\
\hline$\alpha$ & \multicolumn{2}{|c|}{ Elast. of $y$ with respect to $k$} & 0.29 \\
\hline$\theta$ & \multicolumn{2}{|c|}{ Elast. of $y$ with respect to $n$} & 0.35 \\
\hline$\kappa$ & \multicolumn{2}{|c|}{ Fixed cost of production } & 1.02 \\
\hline$\eta$ & \multicolumn{2}{|c|}{ Curvature of the Pareto distr. } & 3.47 \\
\hline$\gamma$ & \multicolumn{2}{|c|}{ New productivity arrival rate } & 0.15 \\
\hline$\phi$ & \multicolumn{2}{|l|}{ Enforcement parameter } & 0.12 \\
\hline$\tau_{0}$ & \multicolumn{2}{|c|}{ Interm. costs - independent factor } & 0.01 \\
\hline$\tau_{a}$ & \multicolumn{2}{|c|}{ Interm. costs - elast. of assets } & 0.68 \\
\hline$\tau_{z}$ & \multicolumn{2}{|c|}{ Interm. costs - elast. of productivity } & 0.23 \\
\hline$\chi$ & \multicolumn{2}{|c|}{ Bank barg. power in a loan } & 0.03 \\
\hline \multicolumn{4}{|c|}{ Model Fit } \\
\hline \multicolumn{2}{|c|}{12 Targeted Moments } & Data & Model \\
\hline \multicolumn{2}{|c|}{ Risk-free bond rate } & 0.02 & 0.02 \\
\hline \multicolumn{2}{|c|}{ Capital's share of income } & 0.40 & 0.28 \\
\hline \multicolumn{2}{|c|}{ Investment rate } & 0.17 & 0.11 \\
\hline \multicolumn{2}{|c|}{ Top $10 \%$ earners' income share } & 0.56 & 0.59 \\
\hline \multicolumn{2}{|c|}{ Average firm size } & 21.0 & 21.2 \\
\hline \multicolumn{2}{|c|}{ Top $10 \%$ firms' employment share } & 0.78 & 0.68 \\
\hline \multicolumn{2}{|c|}{ Firm exit rate } & 0.08 & 0.05 \\
\hline \multicolumn{2}{|c|}{ External finance to GDP ratio } & 0.49 & 0.52 \\
\hline \multicolumn{2}{|c|}{ Fraction firms with credit } & 0.35 & 0.40 \\
\hline \multicolumn{2}{|c|}{ Average spread (unweighted) } & 0.38 & 0.40 \\
\hline \multicolumn{2}{|c|}{ Average spread (credit-weighted) } & 0.06 & 0.06 \\
\hline \multicolumn{2}{|c|}{ Standard deviation of spread } & 0.32 & 0.33 \\
\hline
\end{tabular}

\section{Quantitative Analysis}

We turn now to use the calibrated model to evaluate the quantitative importance of financial frictions. We do so by comparing the results for output, 
wages, TFP, capital, and the credit market under the stationary distributions of different alternative parameter values.

We start by looking at the impacts of spreads vs. quantity constraints on aggregates. The top panel of Table 4 summarizes these impacts by presenting results relative to their values in a counterfactual world of perfect credit; i.e., the same parameter values except no enforcement problems, $\phi=1$, and no intermediary market power, $\chi=0$, or intermediation costs, $\tau_{i}=0$, which lead to spreads. This perfect credit benchmark is illustrated in Column (1).

Column (2) shows the full impact of the calibrated financial frictions in our benchmark economy. The three frictions lead to a considerably lower ratio of credit to GDP, just $47 \%$ of the perfect credit economy. The lack of credit leads to substantially lower capital in the economy, 74\% of the level in the perfect credit counterfactual. Moreover, the credit frictions misallocate capital, which leads to TFP being lower, just $75 \%$ of the perfect credit economy. In aggregate, the lower capital and less well allocated capital leads to GDP being just $69 \%$ of the perfect credit GDP. The level of wages is just $65 \%$ of their level in the perfect credit world. The slightly larger impact on wages is because the credit frictions lead to less entry and fewer entrepreneurs (as seen by the lower exit and larger firms), which means more workers. With Cobb-Douglas technology, the share of income going to labor remains stable, but, divided among more workers, the wage level itself is lower.

Columns (3) and (4) are used to decompose the impact of the more traditional quantity constraints (driven by $\phi$ ) and the impacts of spreads in the benchmark economy. By comparing them with Column (2) and each other, we can see the independent impact of these frictions.

In Column (3), we eliminate the enforcement-driven quantity restriction by setting $\phi=1$, so that all contracts can be perfectly enforced and entrepreneurs face no hard quantity constraints on the amount of capital they borrow. However, financial intermediaries still have market power and face costs to intermediate resources among agents. The impact on the financial market is substantial, with credit/GDP increasing 25 percentage points from the benchmark of 0.47 to 
0.72. Nevertheless, the aggregate gains are more modest: 7 percentage points increases in GDP (0.69 to 0.76 ) and TFP (0.75 to 0.82 ), and just a 4 percentage point increase in capital (0.74 to 0.78 ). The impact on wages is somewhat greater, 11 percentage points (from $0.65 \mathrm{vs}$. 0.76), the result of many more entrepreneurs among those with few assets.

For comparison, Column (4) examines the collective impact of all forces that lead to spreads by setting $\tau_{z}=\tau_{a}=\tau_{0}=\chi=0$. Without spreads, credit to GDP increases 19 percentage points (from 0.47 to 0.66 ). Capital increases by 10 percentage points (0.74 to 0.84 ). GDP is $90 \%$ of the level of the perfect credit model, so intermediation spreads alone account for 21 percentage points $(0.90$ minus 0.69$)$ of output. Spreads account for 20 percentage points (0.95-0.75) of TFP as well, and 27 percentage points $(0.92-0.65)$ of wage. Thus, about twothirds of the losses in output, three-quarters of the loss in wages, and 80 percent of the losses in TFP come through the credit spread channel. Clearly, although quantity constraints are not negligible, credit spreads are the dominant source of frictions in the benchmark model.

Next we contrast our benchmark with counterfactual explanations for the observed financial underdevelopment. That is, in Columns (5) and (6), we calibrate different parameters to match the credit/GDP ratio in the benchmark model (and data). In Column (5), we eliminate all dispersion in spreads by setting the spread dispersion-causing parameters to zero, $\tau_{a}=\tau_{z}=\chi=0$. We then calibrate $\tau_{0}=0.09$ to match the credit to GDP in the benchmark economy. Despite yielding the same level of credit to GDP, a uniform spread does not have the same severity of aggregate impacts as the benchmark. The capital levels are comparable ( 0.73 vs. 0.74 in the benchmark), but GDP ( 0.80 vs. 0.69$)$ and TFP ( 0.88 vs. 0.75 ) are substantially higher without spread dispersion. Hence, modeling both the level and dispersion in spreads is important, especially for TFP. In Column (6), we eliminate all spreads by setting $\tau_{a}=\tau_{z}=\tau_{0}=\chi=0$, and increase the enforcement friction (by decreasing $\phi$ to 0.05 ) in order to again match benchmark credit to GDP. This counterfactual is closest in spirit to the existing literature (e.g., Buera, Kaboski, and Shin, 2011), with only quantity constraints 
Table 4: Impacts of Credit Frictions on Development

\begin{tabular}{|c|c|c|c|c|c|c|}
\hline $\begin{array}{l}\text { Value } \\
\text { Relative to } \\
\text { Perfect } \\
\text { Credit: }\end{array}$ & $\begin{array}{l}\text { Perfect } \\
\text { Credit } \\
\text { (1) }\end{array}$ & $\begin{array}{l}\text { Benchmark } \\
\text { (2) }\end{array}$ & $\begin{array}{c}\text { No } \\
\text { Quant. } \\
\text { Constr. } \\
\text { (3) }\end{array}$ & $\begin{array}{c}\text { No } \\
\text { Spread } \\
\text { Frictions } \\
(4)\end{array}$ & $\begin{array}{c}\text { No } \\
\text { Spread } \\
\text { Disp. } \\
(5)\end{array}$ & $\begin{array}{c}\text { All } \\
\text { Quant. } \\
\text { Constr. } \\
(6)\end{array}$ \\
\hline \multicolumn{7}{|c|}{ Aggregate values relative to perfect credit world: } \\
\hline GDP & 1.00 & 0.69 & 0.76 & 0.90 & 0.80 & 0.86 \\
\hline TFP & 1.00 & 0.75 & 0.82 & 0.95 & 0.88 & 0.92 \\
\hline Wage & 1.00 & 0.65 & 0.76 & 0.92 & 0.84 & 0.87 \\
\hline Capital & 1.00 & 0.74 & 0.78 & 0.84 & 0.73 & 0.80 \\
\hline Credit/GDP & 1.00 & 0.47 & 0.72 & 0.66 & 0.47 & 0.48 \\
\hline Interest rate & 0.13 & 0.02 & 0.05 & 0.06 & 0.01 & 0.01 \\
\hline Firm growth & 0.01 & 0.06 & 0.05 & 0.03 & 0.03 & 0.03 \\
\hline Exit rate & 0.12 & 0.05 & 0.12 & 0.12 & 0.12 & 0.12 \\
\hline Avg. firm size & 9 & 21 & 19 & 9 & 10 & 8 \\
\hline
\end{tabular}

Column (2) parameter values are those calibrated in Table 3 . Relative to these values, Column (1): $\tau_{i}=\chi=0$ and $\phi=1$, Column (3): $\phi=1$, Column (4): $\chi=\tau_{i}=0$, Column (5): $\tau_{a}=\tau_{z}=\chi=0$ and $\tau_{0}=0.09$, and Column (6): $\tau_{i}=\chi=0$ and $\phi=0.05$, calibrated to match credit/GDP in the benchmark and data.

but no spreads. The impacts on aggregates are even milder than in the model without spread dispersion. Capital levels are a bit higher in this world ( $0.80 \mathrm{vs.}$ $0.74)$, but the levels of wages ( 0.87 vs. 0.65$)$, GDP ( 0.86 vs. 0.69$)$, and especially TFP (0.92 vs. 0.75$)$ are markedly higher. Hence, if only quantity restrictions were modeled, the predicted impacts would be less than $80 \%$ (i.e., $(1-0.80) /(1-$ $0.74))$ as large on capital, less than half as large on GDP and less than one-third as large on TFP.

The bottom panel examines the model implications for the interest rate on savings and firm dynamics. All simulations with frictions yield a lower value for the interest rate than the perfect credit world. Although capital falls by slightly more than TFP, the interest rate on savings is substantially lower in the benchmark, just $2 \%$ relative to $13 \%$ in the perfect credit world. With spreads and quantity frictions, there is a decline in demand for credit at any interest rate. These frictions also increase the supply of savings by giving strong motives for 
saving for precautionary and self-financing reasons, and to secure better credit spreads. All of this drives down the interest rate. Comparing the benchmark with the perfect credit world, firm growth is faster (0.06 vs. 0.01 ), exit (which equals entry) is smaller ( 0.05 vs. 0.12$)$, and the average firm has more workers (21 vs. 9) in the benchmark model. Looking at Columns (3) and (4), the faster growth and larger average firm size is driven by spread dispersion. Looking across the columns, the lower exit rate is not driven by any one friction so must arise from the interaction of frictions.

In sum, spread frictions are an important source of the losses from credit market imperfections. Modeling spread dispersion matters since it is quantitatively important for the aggregate impacts of financial frictions on development because it leads to larger losses, especially for TFP.

Given this finding, Table 5 delves into the driving forces behind spread frictions in more depth by evaluating the roles of the various types of spread-causing frictions: market power (governed by $\chi$ ), the uniform intermediation cost $\left(\tau_{0}\right)$, the asset-dependent intermediation $\operatorname{cost}$ (governed by $\tau_{a}$ ), and the productivitydependent intermediation cost (governed by $\tau_{z}$ ). The top panel gives the impacts on aggregates (expressed relative to the perfect credit values), the middle panel presents the remaining spread and credit moments that we target, and the bottom panel shows some measures related to firm dynamics. 
Table 5: Isolated Impacts of Spread-Causing Frictions

\begin{tabular}{|c|c|c|c|c|c|c|c|c|c|}
\hline & \multirow[b]{2}{*}{$\begin{array}{c}\text { Benchmk } \\
\text { (1) }\end{array}$} & \multicolumn{4}{|c|}{ Eliminating Frictions } & \multicolumn{4}{|c|}{ Single Friction Calibrations } \\
\hline & & $\begin{array}{c}\text { No } \\
\text { Market } \\
\text { Power } \\
(2)\end{array}$ & $\begin{array}{l}\text { No } \\
\text { Uniform } \\
\text { Cost } \\
\text { (3) }\end{array}$ & $\begin{array}{c}\text { No } a- \\
\text { depend. } \\
\text { Cost } \\
(4)\end{array}$ & $\begin{array}{l}\text { No } z- \\
\text { depend. } \\
\text { Cost } \\
\text { (5) }\end{array}$ & $\begin{array}{c}\text { All } \\
\text { Market } \\
\text { Power }^{\dagger} \\
(6)\end{array}$ & $\begin{array}{c}\text { All } \\
\text { Uniform } \\
\text { Cost } \\
(7)\end{array}$ & $\begin{array}{c}\text { All } a- \\
\text { depend. } \\
\text { Cost } \\
\text { (8) }\end{array}$ & $\begin{array}{l}\text { All } z- \\
\text { depend. } \\
\text { Cost } \\
\text { (9) }\end{array}$ \\
\hline \multicolumn{10}{|c|}{ Aggregate values relative to perfect credit world: } \\
\hline GDP & 0.69 & 0.69 & 0.69 & 0.75 & 0.72 & 0.55 & 0.82 & 0.40 & 0.82 \\
\hline TFP & 0.75 & 0.75 & 0.76 & 0.80 & 0.77 & 0.64 & 0.90 & 0.52 & 0.88 \\
\hline Wage & 0.65 & 0.66 & 0.66 & 0.72 & 0.67 & 0.51 & 0.87 & 0.47 & 0.83 \\
\hline Capital & 0.74 & 0.73 & 0.75 & 0.81 & 0.78 & 0.60 & 0.75 & 0.43 & 0.80 \\
\hline Credit/GDP & 0.47 & 0.47 & 0.49 & 0.48 & 0.57 & 0.66 & 0.53 & 0.11 & 0.54 \\
\hline \multicolumn{10}{|c|}{ Firm credit spread moments: } \\
\hline Interest rate & 0.02 & 0.02 & 0.02 & 0.03 & 0.04 & 0.04 & 0.03 & 0.00 & 0.02 \\
\hline Avg. (weighted) & 0.06 & 0.06 & 0.05 & 0.05 & 0.03 & 0.02 & 0.06 & 0.06 & 0.06 \\
\hline Avg. (unweighted) & 0.40 & 0.48 & 0.39 & 0.08 & 0.29 & 0.02 & 0.06 & 22.9 & 0.11 \\
\hline Std. deviation & 0.33 & 0.33 & 0.33 & 0.02 & 0.31 & 0.01 & 0.00 & 18.4 & 0.02 \\
\hline Frac. with credit & 0.40 & 0.47 & 0.41 & 0.36 & 0.48 & 0.84 & 0.93 & 0.01 & 0.81 \\
\hline Firm growth & 0.06 & 0.06 & 0.07 & 0.01 & 0.08 & 0.04 & 0.03 & 0.02 & 0.03 \\
\hline Exit rate & 0.05 & 0.06 & 0.06 & 0.04 & 0.06 & 0.01 & 0.12 & 0.00 & 0.12 \\
\hline Avg. firm size & 21 & 19 & 21 & 20 & 21 & 23 & 8 & 7 & 12 \\
\hline \multicolumn{10}{|c|}{$\begin{array}{l}\text { Column (1) parameter values are those calibrated in Table } 3 \text {. Relative to these values, Column (2): } \chi=0 \text {, Column (3): } \tau_{0}=0 \text {, Column } \\
\text { (4): } \tau_{a}=0 \text {, Column (5): } \tau_{z}=0, \text { Column (6): } \tau_{i}=0 \text { and } \chi=0.57 \text {, Column (7): } \tau_{a}=\tau_{z}=\chi=0 \text { and } \tau_{0}=0.06 \text {, Column }(8): \tau_{0}=\tau_{z}=\chi=0 \\
\text { and } \tau_{a}=37.7 \text {, and Column (9): } \tau_{0}=\tau_{a}=\chi=0 \text { and } \tau_{z}=0.30 \text {. For Columns (7)-(9), the calibrated value is chosen to match the weighted } \\
\text { spread in the benchmark. } \\
{ }^{\dagger} \text { : It is difficult for the code to converge when market power is very high. Hence, Column (6) generates a spread of around } 2 \% \text { by } \\
\text { quadrupling the market power relative to the benchmark. }\end{array}$} \\
\hline
\end{tabular}


Columns (2)-(5) shut off one of these individual frictions at a time. These columns highlight the role of each friction in both spreads and aggregate outcomes. Market power and the uniform intermediation cost have little impact in the calibrated benchmark, as the values in Columns (2) and (3) are nearly identical to the benchmark values in Column (1). This reflects the small calibrated values of $\chi(0.03)$ and $\tau_{0}(0.01)$ in the benchmark. The productivitydependent cost also plays a relatively smaller role on aggregates; see Column (5). It does have the largest independent impact on the credit market, however, constraining credit/GDP ( 0.57 without the friction and 0.47 with it), increasing the average weighted spread (from 0.03 to 0.06 ), and limiting the fraction of entrepreneurs with credit (from 0.48 to 0.40 ). When it comes to macro aggregates, the asset-dependent intermediation cost plays the largest independent role. Comparing Column (4) with the benchmark, the friction lowers GDP 6 percentage points, capital and wages by 7 percentage points, and TFP by 5 percentage points. Focusing on the credit market, the friction greatly increases the unweighted average spread (from 0.08 to 0.40 ) and the standard deviation of spread (from 0.02 to 0.33 ), despite only marginally decreasing credit/GDP (from 0.48 to 0.47 ). Thus, $\tau_{a}$ plays the largest independent role. Nevertheless, the total independent impacts of turning off each of the frictions is smaller than the overall impacts of spread frictions. Hence, the interaction of spreadinducing frictions is also important.

Columns (6)-(9) instead load up all the spreads onto a single individual friction, while eliminating the others. For example, Column (6) illustrates that the negligible results in Column (2) are due to the low calibrated levels of market power and not because intermediary market power is inherently benign. Indeed, if the intermediary's bargaining power had been four times larger, output, wages, capital, TFP and assets would all be substantially lower than in the benchmark. More entrepreneurs would get credit (0.84 vs. 0.40$)$, but intermediaries with high market power would charge high spreads on productive firms, capturing their rents and preventing these productive firms from accumulating assets ( 0.60 vs. 0.74$)$ quickly over time and eventually escaping their (quantity) constraints. This would lead to smaller firm growth (0.04 vs. 0.06). 
For Columns (7)-(9), the parameter value governing the isolated intermediation cost friction is calibrated to match the average credit-weighted spread in the benchmark (and data). Column (8) shows that asset-dependent spreads can have large negative impacts on output, wages, capital, TFP, and assets, and even larger impacts on credit to GDP. In this world, spreads are avoidable since assets are endogenous. Therefore, in order to match the high average spread, the calibrated value of $\tau_{a}$ is enormous, 37.7, indicating a person with no assets would pay an interest rate of $3770 \%$ ! These poor entrepreneurs of course do not borrow, leading to a much smaller fraction of entrepreneurs obtaining credit $(0.01$ vs. 0.40$)$. Wealth and not ability therefore drives entrepreneurship decisions, and entry and exit are essentially non-existent. At high interest rates, even the very talented, moderately wealthy borrow very little. Consequently, the unweighted spread is much larger than the weighted spread. (Comparing the unweighted-weighted difference across Columns (6) and (8) highlights how this difference is important in distinguishing market power from asset-dependent frictions.) Columns (7) and (9) show that the uniform and productivity-dependent costs have smaller and similarly-sized impacts on aggregates. The latter do not lead to much variation in spreads, so they resemble uniform costs except that they enable high-productivity entrepreneurs to borrow a bit more capital. Indeed, these impacts resemble the quantity constraint in Table 4 , only somewhat stronger.

Next, we focus on the lower panel to get insight into the faster firm growth, lower exit rates, and larger average firm size in the benchmark. Columns (2)(5) indicate that the faster firm growth hinges on asset-dependent costs. Contrasting Columns (1) and (4), we see that growth is much smaller without assetdependent costs. Although they reduce retained earnings, limiting the firms' ability to grow, they also give incentives for firms to accumulate assets quickly to escape the high spreads. Contrasting Columns (1) and (5), however, we see that the productivity-dependent costs inhibit growth. They decrease the profitability and retained earnings of firms, and lower firms' ability to grow. But, because they are exogenous, they give no additional incentive to grow. However, if we look at Column (8), in a world where all spreads are driven 
by asset-dependent costs, growth is very small. This is because entry and exit are effectively eliminated by the enormous spreads that choke off the ability for firms with minimal assets to be profitable. Hence, in addition to the ability and incentives to grow, spreads affect firm growth through their impact on entry, exit, and selection into entrepreneurship given the endogenous wealth dynamics that precede it.

Finally, note that all four of the alternative worlds in Columns (6)-(9) lead to lower average firm growth rates than in the benchmark, which implies that the interaction of different spread-causing frictions is important in explaining the benchmark's higher firm growth rate. Similarly, Columns (2)-(5) indicate that the interactions are important for explaining the higher firm size in the benchmark.

\section{Life Cycle Dynamics in Data and Model}

We now examine the firm dynamics in the model and data in more depth as an additional testable implication of the model's mechanisms. To compare with the data, we use the model to generate a Monte Carlo simulation of a population of agents. From this sample, we generate a comparably large sample of firms 18 Recall that our data for Brazil contain annual observations of firm size (number of employees), spreads, and age but lack data on capital and, consequently, productivity. We therefore focus our analysis on the life cycle dynamics of firms. We first evaluate the life cycle pattern of spreads to evaluate our mechanism and then turn to its implications for firm size dynamics.

\footnotetext{
${ }^{18}$ The samples are not identical, since entry is endogenous in the Monte Carlo simulation, but both samples are so large that the difference is irrelevant.
} 


\subsection{Spread Patterns}

By construction, our model reproduces some moments of the level and variation of spreads, but it also predicts that spreads have components that vary both across firms and over their life cycles. Much of the former variation is exogenous, whereas the latter is endogenous. An important question is whether these patterns are quantitatively consistent with those in the data. Table 6 compares the results of regressions of $\ln \left(1+\right.$ spread $_{i, t}$ on firm $i$ characteristics. Columns (1)-(3) simply reproduce the the residual regression results in Columns (2), (3), and (5) of Table 2. (Recall that the constants are less meaningful since the data are residuals of regressions on loan controls and time fixed effects.) We compare these to the model analogs in Columns (4)-(6). Both model and data show a significant, declining but convex life cycle of spreads. Moreover, fixed effects play important roles, increasing the $R^{2}$ roughly 50 percentage points in the data-moving from Column (1) to (2)-and 40 percentage points in the model-moving from Column (4) to (5). Finally, controlling for fixed effects, the spread is increasing in wage bill in both model and data. The patterns show remarkable qualitative consistency.

However, three important distinctions between the model and data should be noted. First, the regression explains much more of the variation in spreads in the model than in the data. Second, the t-statistics are much larger in the simulated data. Third, the root mean-squared error (RMSE) in the data is 0.179, whereas it is just 0.021 in the model. Our parsimonious model contains only two dimensions that vary spreads (productivity, $z$, and assets, $a$ ). Fixed effects, wage bill, and age together capture a great deal of this variation. Naturally, in the data, there are many additional unmodeled sources of variation, and the RMSEs reflect the simplicity of model vs. data.

Nevertheless, the lifecycle dynamics of spreads that the regressions imply are similar in the model and data. Concretely, the data estimates in Column (2) imply a drop of $5(\mathrm{log})$ percentage points in the spread between entry and age 15 , while the model estimates imply a drop of $9(\log )$ percentage points over 
Table 6: Spreads and Firm Characteristics - Data vs. Model

\begin{tabular}{lccc|ccc}
\hline \hline & & \multicolumn{3}{c|}{ Data $^{\dagger}$} & \multicolumn{3}{c}{ Model } \\
& $(1)$ & $(2)$ & $(3)$ & $(4)$ & $(5)$ & $(6)$ \\
\hline Constant & $0.0067^{* * *}$ & $0.0416^{* * *}$ & $0.0307^{* * *}$ & $0.4419^{* * *}$ & $0.1550^{* * *}$ & $0.0924^{* * * *}$ \\
& {$[57.04]$} & {$[12.62]$} & {$[5.37]$} & {$[1974.86]$} & {$[585.91]$} & {$[388.92]$} \\
Age & $-0.0007^{* * *}$ & $-0.0041^{* * *}$ & $-0.0042^{* * *}$ & $-0.0240^{* * *}$ & $-0.0078^{* * *}$ & $-0.0056^{* * *}$ \\
& {$[-66.92]$} & {$[-12.31]$} & {$[-13.24]$} & {$[-1443.73]$} & {$[-569.91]$} & {$[-458.34]$} \\
Age ${ }^{2}$ & $0.0000^{* * *}$ & $0.0000^{* * *}$ & $0.0000^{* * *}$ & $0.0003^{* * *}$ & $0.0001^{* * *}$ & $0.0001^{* * *}$ \\
& {$[57.59]$} & {$[11.63]$} & {$[12.50]$} & {$[958.16]$} & {$[580.37]$} & {$[957.74]$} \\
Wagebill (ln) & & & $0.0015^{* * *}$ & & & $0.0303^{* * *}$ \\
& & & {$[2.75]$} & & & {$[1406.18]$} \\
& & & & & & \\
\hline Loan controls & Yes & Yes & Yes & - & - & - \\
Time FE & Yes & Yes & Yes & Yes & Yes & Yes \\
Firm FE & No & Yes & Yes & No & Yes & Yes \\
Observations & $11,846,236$ & $11,846,236$ & $10,850,982$ & $7,407,211$ & $7,407,211$ & $7,407,211$ \\
R-squared & 0.000 & 0.539 & 0.541 & 0.531 & 0.931 & 0.947 \\
RMSE & 0.226 & 0.179 & 0.178 & 0.054 & 0.021 & 0.019 \\
\hline \hline
\end{tabular}

The dependent variable is $\ln (1+\text { spread })_{i, t}$, residualized of loan controls, time FEs in the data. $\dagger$ The "Data" results reproduce the residual regressions in Columns (2), (3), and (5) of Table 2. $t$ statistics in parentheses; ${ }^{*} p<0.1,{ }^{* *} p<0.05,{ }^{* * *} p<0.01$

the same years. ${ }^{19}$ The shapes of these dynamics are also similar. Moreover, both magnitudes are reasonable in relation to other work. For example, Midrigan and $\mathrm{Xu}$ (2014) report drops in average product of capital (which equals marginal product of capital in their model and our model) of 15 percentage points in China and 21 percentage points in Korea but an increase of 25 percentage point in Colombia over the lifecycle. The spread dynamics are important, since they impact the ability and incentives to accumulate assets endogenously. We turn now to the implications of spreads for firm size dynamics.

\footnotetext{
${ }^{19}$ We have normalized the spreads to zero upon entry. Recall that the level of spreads are calibrated to match in the model and data.
} 


\subsection{Firm Growth}

To capture patterns of firm size with respect to credit and life cycle in the model and data, we regress the growth of firm $i, \frac{n_{i, t}}{n_{i, t-1}}$ on a quadratic in age, $h_{i, t}$, an indicator of whether or not a firm borrowed, $\mathbb{I}_{\text {loan }, i, t}$, and the (log of the gross) spread, $\ln \left(1+\right.$ spread $_{i, t}$ :

$$
\frac{n_{i, t}}{n_{i, t-1}}=\beta_{i}+\beta_{a} h_{i, t}+\beta_{a^{2}} h_{i, t}^{2}+\beta_{\text {loan }} \mathbb{I}_{\text {loan }, i, t}+\beta_{\tilde{r}} \ln (1+\text { spread })_{i, t}+\varepsilon_{i, t} .
$$

We do this with and without fixed effects, $\beta_{i}$, though we note that the regression form, which uses growth, implicitly allows for a firm-specific fixed effect in size. The results are presented in Table 7 below.

Once again, we compare the results in Columns (1)-(3) (data) to those in Columns (4)-(6) model. Most firms in both the model and data are relatively young, so the age coefficients reflect a declining, convex relationship of growth over the first 15 years of lifecycle and the corresponding concave increase in size over the first 15 years. Comparing Columns (3) and (6), in particular, we see that firms with loans and firms paying higher spreads tend to grow significantly faster. The magnitudes of the estimated relationships are much larger in the model, however: the coefficient on having a loan is 9 times higher, while the coefficient on spreads is 50 times higher.

Again, however, we do not see this as reflecting that the strength of the spread and loan relationships is too strong in the model. Rather, we interpret it as merely an artifact of a parsimonious model with spreads that depend on only two variables, productivity and assets. To examine this, we add an additive component to the explanatory spread variable as an additional source of spread variation. Specifically, we add a mean zero, random variable that is normally distributed with a standard deviation of 0.158 (the above noted difference in RMSE of 0.179 and 0.021 in Table 6) and is independently and identically distributed (iid) over time and firms. Moreover, we add an additional source of variation into the "have loan" indicator by adding a similar mean zero, iid random normal variable with a standard deviation $1.627\left(=10.3^{*} 0.158\right.$, where the 
Table 7: Firm Growth Patterns $\log \left(\frac{n_{t}}{n_{t-1}}\right)$ - Data vs. Model

\begin{tabular}{lccc|cccc}
\hline \hline & & Data & \multicolumn{4}{c}{ Model } \\
& $(1)$ & $(2)$ & $(3)$ & $(4)$ & $(5)$ & $(6)$ & $(7)^{\dagger}$ \\
\hline Constant & $0.0647^{* *}$ & $0.2623^{* * *}$ & $0.2456^{* * *}$ & $0.0450^{* * *}$ & $0.1555^{* * *}$ & $-0.1693^{* * *}$ & $0.1356^{* * * *}$ \\
& {$[2.23]$} & {$[5.82]$} & {$[5.42]$} & {$[41.47]$} & {$[47.20]$} & {$[-53.91]$} & {$[41.18]$} \\
Age & $-0.0057^{* * *}$ & $-0.0132^{* * *}$ & $-0.0134^{* * *}$ & $-0.0049^{* * *}$ & $-0.0088^{* * *}$ & $0.0067^{* * *}$ & $-0.0084^{* * *}$ \\
& {$[-22.00]$} & {$[-32.39]$} & {$[-32.85]$} & {$[-61.50]$} & {$[-52.80]$} & {$[42.16]$} & {$[-50.01]$} \\
Age ${ }^{2}$ & $0.0000^{* * *}$ & $0.0001^{* * *}$ & $0.0001^{* * *}$ & $0.0001^{* * *}$ & $0.0001^{* * *}$ & $-0.0001^{* * *}$ & $0.0001^{* * *}$ \\
& {$[21.12]$} & {$[31.49]$} & {$[31.97]$} & {$[66.53]$} & {$[54.82]$} & {$[-42.91]$} & {$[52.05]$} \\
Have loan & & & $0.0310^{* * *}$ & & & $0.2834^{* * *}$ & $0.0207^{* * * *}$ \\
& &. & {$[15.87]$} & & & {$[143.33]$} & {$[114.81]$} \\
ln(1+spread) & & & $0.0415^{* * *}$ & & & $1.9889^{* * *}$ & $0.0490^{* * *}$ \\
& & & {$[9.40]$} & & & {$[115.91]$} & {$[86.97]$} \\
& & & & & & & \\
\hline Loan controls & Yes & Yes & Yes & - & - & - & - \\
Time FE & Yes & Yes & Yes & Yes & Yes & Yes & Yes \\
Firm FE & No & Yes & Yes & No & Yes & Yes & Yes \\
Observations & $9,167,466$ & $9,167,466$ & $9,127,081$ & $6,992,261$ & $6,992,261$ & $6,992,261$ & $6,992,261$ \\
R-squared & 0.049 & 0.286 & 0.287 & 0.0008 & 0.0299 & 0.1312 & 0.0330 \\
RMSE & 0.525 & 0.527 & 0.526 & 0.226 & 0.230 & 0.218 & 0.230 \\
\hline \hline
\end{tabular}

$\dagger$ In the simulated results in Column (7), random normal, i.i.d. errors have been added to the spread and got loan controls, calibrated to match the unexplained spread variation in the model to the data. $t$ statistics in parentheses; ${ }^{*} p<0.1,^{* *} p<0.05,{ }^{* * *} p<0.01$

10.3 scale coefficient reflects the coefficient of a regression of credit on spreads) to our measure of credit. We then reconstruct the have loan to indicate any firm with positive credit. Column (7) reflects this regression. The coefficients are comparable once an additional source of variation is added.

Finally, we examine the quadratic life cycle dynamics of entering firms implied by these regressions by plotting size relative to entry size over time. We choose Columns (1) and (4) for the data and benchmark model, respectively, without growth fixed effects, since this is more comparable with prior empirical work. Moreover, we run an analogous regression on simulated data from the model 
Figure 2: Firm Dynamics

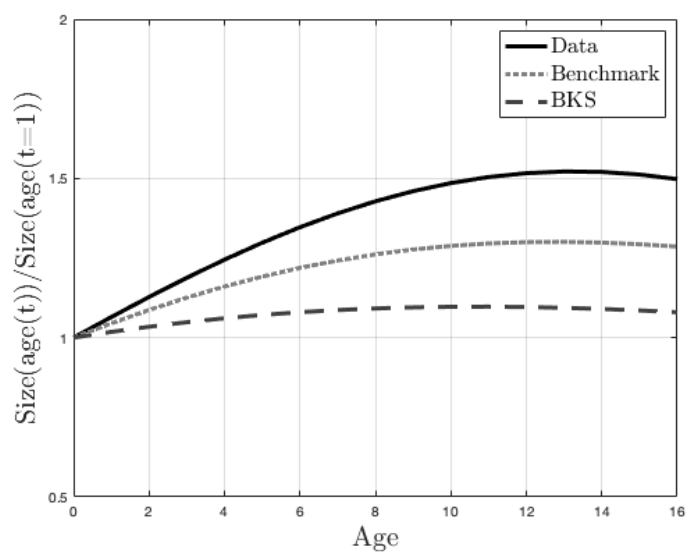

(a) Relative firm size by age.

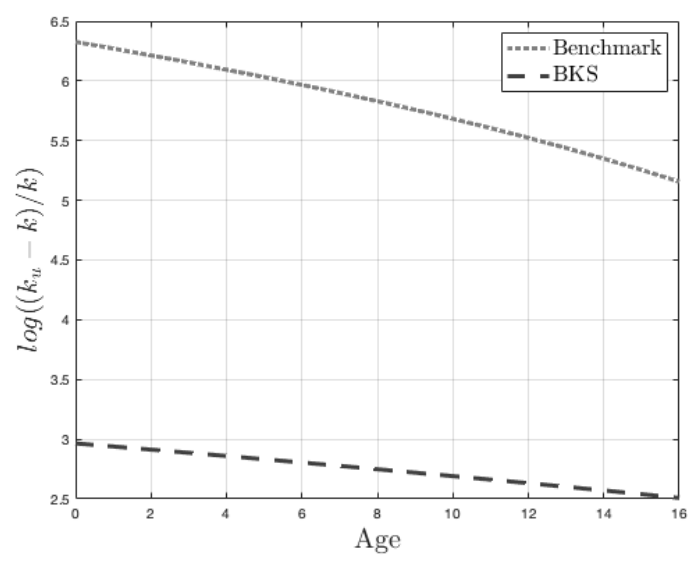

(b) $\log \left(\left(k_{u}-k\right) / k\right)$ by age.

Notes: Benchmark is the full model with both a quantity constraint and spread frictions. BKS is a model with only a quantity constraint (as in Buera, Kaboski, and Shin, 2011) recalibrated to match the same level of credit/GDP as in Column (6) of Table 4

with only quantity constraints as a third comparison ${ }^{20}$

Figure 2(a) plots these quadratic life cycle dynamics for the data, our benchmark model, and the calibrated version of our model with only quantity constraints (i.e., Column (6) in Table 4). In the data (solid line), firm size in Brazil is essentially increasing but concave in age over the first 15 years of firm life, on average rising to just over 150 percent of its entry size ${ }^{21}$ The dynamics of a more standard model with only quantity constraints (dashed line) shows very little growth, peaking at roughly 10 percent total. The results from our benchmark model (light dotted line) are in between, exhibiting the hump shape but with growth of about 30 percent rather than the 50 percent in the data.

The right panel demonstrates the importance of life cycle dynamics for the aggregate misallocation by plotting (the log of) the percentage gap between un-

\footnotetext{
${ }^{20}$ More specifically, as in Column (4) of Table 4, we set spreads to zero and adjust $\phi$ to match the credit to output ratio observed in the data.

${ }^{21}$ This growth is significantly less than the lifecycle growth for manufacturing plants reported by Hsieh and Klenow (2014) for the U.S., which show 8-fold average growth over 30 years, but greater than the roughly 1.25-fold increase reported for India.
} 
constrained capital and actual capital over the life cycle. The benchmark model starts out with firms that are far more constrained on average, leading to higher levels of misallocation. Nevertheless, the life cycle dynamics demonstrate how this gap is partially closed by faster growth. Hence, aggregate misallocation is linked tightly to faster firm growth, a reflection of both larger initial misallocation and incentives to grow quickly.

\section{Conclusion}

In this paper, we explored the effects of dispersion in financing costs on aggregate development and firm dynamics. Using rich administrative firm-level data sets, we presented evidence of the high level and variation of interest rate spreads on firm's credit in Brazil.

Moreover, we augmented a standard model of credit-constrained entrepreneurs with interest rate spreads that arise from intermediation costs and financial intermediaries' market power. We calibrated the model to match key characteristics of the Brazilian economy. The quantitative results show that credit spreads have larger impacts on development aggregates than the collateral constraints typically considered in the literature. Our findings therefore indicate that financial frictions are more important than previously believed and that interest rate spreads are an important friction to consider.

Our study also motivates future work on the causes of credit spreads to improve financial development. Spreads arising from market power or falling disproportionately on small firms are particularly harmful, so they should get more focus in policy discussions and research. In particular, empirically identifying the sources of these frictions is important. 


\section{References}

Abeles, M., V. Amarante, And D. Vega (2015): “The Earnings Share of Total Income in Latin America, 1990-2010," Cepal Review, 29-49.

Achdou, Y., J. HAN, J.-M. LAsry, P.-L. Lions, AND B. Moll (2021): “Income and Wealth Distribution in Macroeconomics: A Continuous-Time Approach," The Review of Economic Studies, forthcoming.

Antunes, A., T. Cavalcanti, And A. Villamil (2008): “The Effect of Financial Repression and Enforcement on Entrepreneurship and Economic Development," Journal of Monetary Economics, 55, 278 - 297.

Attanasio, O. P. And G. Weber (2010): “Consumption and Saving: Models of Intertemporal Allocation and Their Implications for Public Policy," Journal of Economic Literature, 48, 693-751.

BAI, Y., D. LU, AND X. TIAN (2018): “Do Financial Frictions Explain Chinese Firms' Saving and Misallocation?" NBER Working Papers 24436, National Bureau of Economic Research, Inc.

BANERJEe, A. V. (2003): “Contracting Constraints, Credit Markets, and Economic Development," in Advances in Economics and Econometrics: Theory and Applications, Cambridge University Press, vol. 3, 1.

BANERJEe, A. V. AND E. Duflo (2005): "Growth Theory through the Lens of Development Economics," in Handbook of Economic Growth, ed. by P. Aghion and S. N. Durlauf, Amsterdam: Elsevier, vol. 1A, 473-552.

(2010): "Giving Credit Where It Is Due," Journal of Economic Perspectives, $24,61-80$.

Banerjee, A. V. ANd B. Moll (2010): “Why Does Misallocation Persist?" American Economic Journal: Macroeconomics, 2, 189-206.

Besley, T., K. Burchardi, And M. GhataK (2017): “The Gains from Financial Inclusion: Theory and a Quantitative Assessment," working paper, London School of Economics. 
Buera, F. J., J. P. KAbOSKI, AND Y. SHIN (2011): “Finance and Development: A Tale of Two Sectors," American Economic Review, 101, 1964-2002.

- (2020): "The Macroeconomics of Microfinance," The Review of Economic Studies, 88, 126-161.

Buera, F. J. AND Y. SHin (2013): “Financial Frictions and the Persistence of History: A Quantitative Exploration," Journal of Political Economy, 121, 221272.

Bustos, P., G. Garber, AND J. Ponticelli (2020): “Capital Accumulation and Structural Transformation*," The Quarterly Journal of Economics, 135, 1037-1094.

DAmOdaran, A. (2020): “Country Risk: Determinants, Measures and Implications - The 2020 Edition," Working Paper, NYU Stern School of Business.

David, J. M. And V. Venkateswaran (2019): “The Sources of Capital Misallocation," American Economic Review, 109, 2531-2567.

ERosA, A. (2001): "Financial Intermediation and Occupational Choice in Development," Review of Economic Dynamics, 4, 303-334.

Fajardo, J., J. ORnelas, AND . A. FARIAS (2012): “Estimating Risk Aversion, Risk-Neutral and Real-World Densities Using Brazilian Real Currency Options," Economia Aplicada, 16, 567-577.

Feenstra, R., R. InlaAR, AND M. Timmer (2015): “The Next Generation of the Penn World Table," American Economic Review, 105, 3150-3182.

Gandelman, N. AND R. HeRnÁndeZ-Murillo (2014): "Risk Aversion at the Country Level," Federal Reserve Bank of St. Louis Working Papers 2014-5.

Gilchrist, S., J. W. Sim, AND E. ZAKRAJSeK (2013): “Misallocation and Financial Market Frictions: Some Direct Evidence from the Dispersion in Borrowing Costs," Review of Economic Dynamics, 16, 159-176. 
Gollin, D. (2002): "Getting Income Shares Right," Journal of Political Economy, $110,458-474$.

Gopinath, G., Kalemli-Özcan, L. Karabarbounis, and C. VillegasSANCHEZ (2017): "Capital Allocation and Productivity in South Europe," The Quarterly Journal of Economics, 132, 1915-1967.

GReEnWoOd, J., J. M. SANChEZ, AND C. WANG (2010): “Financing Development: The Role of Information Costs," American Economic Review, 100, 187591.

HsieH, C.-T. AND P. J. Klenow (2009): "Misallocation and Manufacturing TFP in China and India*," The Quarterly Journal of Economics, 124, 1403-1448.

- (2014): "The Life Cycle of Plants in India and Mexico *," The Quarterly Journal of Economics, 129, 1035-1084.

ITSKHOKI, O. AND B. Moll (2019): “Optimal Development Policies With Financial Frictions," Econometrica, 87, 139-173.

JEONG, H. AND R. M. TOWNSEND (2007): "Sources of TFP Growth: Occupational Choice and Financial Deepening," Economic Theory, 32, 197-221.

MidRigan, V. AND D. Y. XU (2014): “Finance and Misallocation: Evidence from Plant-Level Data," American Economic Review, 104, 422-58.

Moll, B. (2014): “Productivity Losses from Financial Frictions: Can SelfFinancing Undo Capital Misallocation?" American Economic Review, 104, 3186-3221.

Moll, B., R. M. TOWNSEND, AND V. ZHORIN (2017): “Economic development, flow of funds, and the equilibrium interaction of financial frictions," Proceedings of the National Academy of Sciences, 114, 6176-6184.

Morgan, M. (2017): “Falling Inequality beneath Extreme and Persistent Concentration: New Evidence for Brazil Combining National Accounts, Surveys and Fiscal Data, 2001-2015," WID.world WORKING PAPER SERIES 2017/12. 
Sraer, D. And D. Thesmar (2018): "A Sufficient Statistics Approach for Aggregating Firm-Level Experiments," NBER Working Papers 24208, National Bureau of Economic Research, Inc. 